\title{
SUPECA kinetics for scaling redox reactions in networks of mixed substrates and consumers and an example application to aerobic soil respiration
}

\author{
Jin-Yun Tang and William J. Riley \\ Earth and Environmental Sciences Area, Lawrence Berkeley National Laboratory, Berkeley, CA, 94720, USA \\ Correspondence to: Jin-Yun Tang (jinyuntang@lbl.gov)
}

Received: 24 February 2017 - Discussion started: 8 March 2017

Revised: 28 July 2017 - Accepted: 1 August 2017 - Published: 5 September 2017

\begin{abstract}
Several land biogeochemical models used for studying carbon-climate feedbacks have begun explicitly representing microbial dynamics. However, to our knowledge, there has been no theoretical work on how to achieve a consistent scaling of the complex biogeochemical reactions from microbial individuals to populations, communities, and interactions with plants and mineral soils. We focus here on developing a mathematical formulation of the substrate-consumer relationships for consumer-mediated redox reactions of the form $A+B \stackrel{E}{\rightarrow}$ products, where products could be, e.g., microbial biomass or bioproducts. Under the quasi-steady-state approximation, these substrate-consumer relationships can be formulated as the computationally difficult full equilibrium chemistry problem or approximated analytically with the dual Monod (DM) or synthesizing unit (SU) kinetics. We find that DM kinetics is scaling inconsistently for reaction networks because (1) substrate limitations are not considered, (2) contradictory assumptions are made regarding the substrate processing rate when transitioning from single- to multi-substrate redox reactions, and (3) the product generation rate cannot be scaled from one to multiple substrates. In contrast, SU kinetics consistently scales the product generation rate from one to multiple substrates but predicts unrealistic results as consumer abundances reach large values with respect to their substrates. We attribute this deficit to SU's failure to incorporate substrate limitation in its derivation. To address these issues, we propose SUPECA (SU plus the equilibrium chemistry approximation - ECA) kinetics, which consistently imposes substrate and consumer mass balance constraints. We show that SUPECA kinetics satisfies the partition principle, i.e., scaling invariance across
\end{abstract}

a network of an arbitrary number of reactions (e.g., as in Newton's law of motion and Dalton's law of partial pressures). We tested SUPECA kinetics with the equilibrium chemistry solution for some simple problems and found SUPECA outperformed SU kinetics. As an example application, we show that a steady-state SUPECA-based approach predicted an aerobic soil respiration moisture response function that agreed well with laboratory observations. We conclude that, as an extension to SU and ECA kinetics, SUPECA provides a robust mathematical representation of complex soil substrate-consumer interactions and can be applied to improve Earth system model (ESM) land models.

\section{Introduction}

Near-surface soils hold more than twice the carbon in the current atmosphere; therefore, a small change in land carbon dynamics can imply significant feedbacks to the ongoing climate warming (Ciais et al., 2013). This sensitivity has motivated research to better understand Earth's land biogeochemical cycles, both for prediction and assessing the efficacy of climate mitigation and adaptation strategies. To date, however, soil biogeochemical models suffer from high uncertainty (e.g., Arora et al., 2013; Bouskill et al., 2014; Friedlingstein et al., 2014; He et al., 2016). For instance, eight CMIP5 Earth system models (ESMs) predicted that net land carbon uptake varies from 22 to $456 \mathrm{Pg} \mathrm{C}$ for the 20062100 period under the Representative Concentration Pathway 4.5 (RCP4.5; Shao et al., 2013). Similarly, Todd-Brown et al. (2013) estimated that 16 CMIP5 ESMs predicted con- 
temporary global soil carbon stocks ranging from 510 to $3040 \mathrm{Pg} \mathrm{C}$ to $1 \mathrm{~m}$ depth, while the most recent empirical estimation is $1408 \pm 154 \mathrm{Pg} \mathrm{C}$ to $1 \mathrm{~m}$ depth and $2060 \pm 217 \mathrm{Pg} \mathrm{C}$ to $2 \mathrm{~m}$ depth (Batjes, 2016).

The predictive power of existing land biogeochemical models is diminished by uncertainties from structural design, numerical implementation, model parameterization, initial conditions, and forcing data (Tang and Zhuang, 2008; Tang et al., 2010; Luo et al., 2015; Wieder et al., 2015a; Blanke et al., 2016; Tang and Riley, 2016). Among these, developing better model structures and mathematical formulations have been identified as priorities. One proposed structural improvement is to include explicit microbial dynamics (Wieder et al., 2015b), which may enable better predictions of global soil carbon stocks (Wieder et al., 2013), priming effects (Sulman et al., 2014), vertical soil carbon profiles (Riley et al., 2014; Dwivedi et al., 2017), and respiratory temperature sensitivity (Tang and Riley, 2015). A second proposal is to explicitly resolve ecosystem nutrient cycles, following the hypothesis that the potential for increasing land ecosystem carbon uptake from atmospheric $\mathrm{CO}_{2}$ fertilization could be limited by nutrient availability (Vitousek, 1982; Shi et al., 2016; Wieder et al., 2015c).

A common feature that underlies these two proposed model structural improvements is substrate-consumer interactions, which affect microbial substrate decomposition (Grant et al., 1993; Tang and Riley, 2013a; Riley et al., 2014; Le Roux et al., 2016), mineral soil interactions with adsorptive substrates (Smith, 1979; Grant et al., 1993; Resat et al., 2012; Tang and Riley, 2015; Dwivedi et al., 2017), and plantmicrobe competition for nutrients (Grant, 2013; Zhu et al., 2016a, b, 2017). In soil, because there are many consumers competing for many substrates in different places at different times, soil biogeochemical models must be able to scale consistently across space, time, and processes. Scaling across spatial and temporal dimensions is achieved through spatial and temporal discretization and integration, which has been intensively studied elsewhere (e.g., Kolditz et al., 1998; Mao et al., 2006). Here, we examine scaling along the less-studied third dimension (process), focusing on development of a consistent mathematical formulation of substrate-consumer interactions.

Previously, we studied a simple configuration of this consumer-substrate interaction, i.e., the network of singlesubstrate Monod-type reactions (discussed later), and developed a scaling method, the equilibrium chemistry approximation (ECA) kinetics (Tang and Riley, 2013a). ECA kinetics significantly improved the modeling of plant-microbial nutrient competition in the ACME land biogeochemical model (Zhu and Riley, 2015; Zhu et al., 2016a, b, 2017) and was recently cited as one of the most promising methods to improve representation of nutrient competition in ESMs (Achat et al., 2016; Niu et al., 2016). The ECA method also successfully explained why organomineral interactions can slow soil organic matter decomposition rates and how lignin- cellulose ratios (Melillo et al., 1989) can be stabilized during litter decomposition (Tang and Riley, 2013a, 2015).

Following Tang and Riley (2013a), we start our analysis here by assuming a certain homogeneous space-timeprocess unit in soil, within which there are generally three types of substrate-consumer relationships: (1) singlesubstrate Monod-type (also known as $A-E$ type) reactions in the form of $A \stackrel{E}{\rightarrow}$ products; (2) two-substrate (also known as $A B-E$ type) redox reactions in the form of $A+$ $B \stackrel{E}{\rightarrow}$ products, where substrate $A$ and $B$ are called complementary because they both are required for the redox reaction to proceed; and (3) multi-substrate $(>2)$ reactions $\sum_{i} A_{i} \stackrel{E}{\rightarrow}$ products. The scaling of single-substrate Monodtype reactions has been extensively discussed in Tang and Riley (2013a) and is resolved with ECA kinetics (further discussion on ECA kinetics for process scaling will be provided in later sections when discussing SUPECA kinetics). Further, because many multi-substrate reactions can be separated into a combination of single-substrate reactions and redox reactions, our discussion below focuses on achieving a consistent kinetic scaling from a single redox reaction to many reactions in a network.

Mathematically, the problem can be addressed with an explicit formulation of all kinetic processes using ordinary differential equations accounting for all substrates and consumers (Chellaboina et al., 2009). However, such a formulation would require too many parameters and would be numerically very difficult to solve because of its multitemporal scale nature. By making the quasi-steady-state approximation (QSSA), i.e., assuming that product generation from the consumer-substrate complex is much slower than equilibration between consumers, substrates, and consumersubstrate complexes (Briggs and Haldane, 1925; Pedersen et al., 2008), the full kinetic problem is reduced to the simpler equilibrium chemistry (EC) form (e.g., Chellaboina et al., 2009). However, the EC formulation is also usually very difficult to solve numerically. Therefore, analytical approximations to the EC formulation are generally made.

Two classic analytical approximations for modeling redox reactions are dual Monod (DM) kinetics (e.g., Yeh et al., 2001) and the synthesizing unit (SU) approach (Kooijman, 1998; Brandt et al., 2003). Although both of these are special cases of the EC formulation (Kooijman, 2010; Tang and Riley, 2013a), they make different assumptions regarding the relative magnitudes of involved kinetic parameters. For this, Kooijman (2010) has shown that DM kinetics requires the consumer-substrate complex dissociation rate to be much larger than the product generation rate from the complexes. In contrast, single-substrate Monod kinetics (Monod, 1949) or Michaelis-Menten (MM) kinetics (Michaelis and Menten, 1913, which is mathematically identical to the empirical Monod kinetics) does not impose this requirement on its parameters. Moreover, in applications 
to $r$ - $K$ scaling (e.g., Tilman, 1982; Litchman and Klausmeier, 2008), single-substrate Monod kinetics requires the product-generation rate to be faster than the dissociation rate of consumer-substrate complexes. This contrasting requirement on the relative magnitudes of parameters, as we will show later, implies that DM kinetics cannot achieve consistent scaling of substrate-consumer interactions for generic biogeochemical modeling.

We define a kinetic formulation to have consistent process scaling when the formulated substrate-consumer relationship (1) can seamlessly transition from a single substrateconsumer pair to a network of many substrate-consumer pairs without changing its mathematical form (also known as the partition principle as in Newton's second law of motion; Feynman et al., 1963) and (2) does not predict any singularity over the range of substrate and consumer concentrations (also known as the non-singular principle; e.g., Schnell and Maini, 2000; Tang, 2015). The full kinetics and EC formulations both satisfy these two criteria, which can be explained using the following example network of consumer-substrate relationships:

$S_{i}+E_{j} \underset{k_{1, i j}^{-}}{\stackrel{k_{1, i j}^{+}}{\longrightarrow}} E_{j} S_{i} \stackrel{k_{2, i j}^{+}}{\rightarrow} P_{i j}+E_{j}$,

where substrate $S_{i}$ complexes with consumer $E_{j}$ to form complex $E_{j} S_{i}$, which is then degraded into product $P_{i j}$ and a free consumer. Throughout this study, forward and backward kinetic parameters are indicated with superscript "+" and "-", respectively. Unless an ambiguity needs clarification, we assume all variable units are consistently defined.

The full kinetic formulation for the network of Eq. (1) is

$$
\begin{aligned}
& \frac{\mathrm{d}\left[S_{i}\right]}{\mathrm{d} t}=-\left[S_{i}\right] \sum_{j}\left(k_{1, i j}^{+}\left[E_{j}\right]\right)+\sum_{j}\left(k_{1, i j}^{-}\left[E_{j} S_{i}\right]\right) \\
& \frac{\mathrm{d}\left[E_{j} S_{i}\right]}{\mathrm{d} t}=k_{1, i j}^{+}\left[S_{i}\right]\left[E_{j}\right]-\left(k_{1, i j}^{-}+k_{2, i j}^{+}\right)\left[E_{j} S_{i}\right] \\
& \frac{\mathrm{d}\left[E_{j}\right]}{\mathrm{d} t}=-\left[E_{j}\right] \sum_{i}\left(k_{1, i j}^{+}\left[S_{i}\right]\right)+\sum_{i}\left(\left(k_{1, i j}^{-}\right.\right. \\
& \left.\left.+k_{2, i j}^{+}\right)\left[E_{j} S_{i}\right]\right),
\end{aligned}
$$

where $[x]$ indicates the concentration of $x$.

The first summation in Eqs. (2) and (4) satisfies the partition principle. For instance, for Eq. (4), by defining an appropriate mean specific substrate affinity $k_{1, j}^{+}$, the summation $\sum_{i}\left(k_{1, i j}^{+}\left[S_{i}\right]\right)$ can be recast into $k_{1, j}^{+}[S]$, in which $[S]=$ $\sum_{i}\left[S_{i}\right]$ resembles Dalton's law of partial pressures (and many other similar relationships in physics, e.g., Newton's second law of motion; Feynman et al., 1963).

Meanwhile, that the full kinetic formulation satisfies the non-singular principle can be verified by noting that, at any time,

$\left[S_{i}\right]+\sum_{j}\left[E_{j} S_{i}\right]=\left[S_{i}\right]_{T}$,

and that consumption of $S_{i}$ is through generation of product from $\left[E_{j} S_{i}\right]$. Therefore, by combining Eqs. (2), (3), and (5), the overall consumption rate of $S_{i}$ (i.e., $\sum_{j} k_{2, i j}^{+}\left[E_{j} S_{i}\right]$ ) is always smaller than $\left[S_{i}\right]_{T} \sum_{j} k_{2, i j}^{+}$, even when consumers have high abundances relative to their substrates, a common situation in in vivo cells (Sols and Marco, 1970) and in plantmicrobial competition for limited soil nutrients (Vitousek, 1982; Schimel and Bennett, 2004; Vitousek et al., 2010).

Since the EC formulation is obtained by applying the QSSA to the full kinetic formulation (i.e., $\mathrm{d}\left[E_{j} S_{i}\right] / \mathrm{d} t \approx 0$ for Eq. 3), it automatically satisfies the two criteria for consistent process scaling. However, Monod kinetics is scaling inconsistently when it is applied, for example, to singlesubstrate competition by multiple populations or to multisubstrate consumption by a single population (e.g., Williams, 1973; Schnell and Mendoza, 2000; Tang et al., 2010; Riley et al., 2011, 2014; Allison, 2012; Bouskill et al., 2012; Wieder et al., 2013, 2014). Specifically, the notion that Monod kinetics violates the partition principle can be shown from the following inequality:

$F_{j}=\left[E_{j}\right] \sum_{i} \frac{k_{2, i j}^{+}\left[S_{i}\right]}{K_{i j}+\left[S_{i}\right]} \neq\left[E_{j}\right] \frac{\sum_{i} k_{2, i j}^{+}\left[S_{i}\right] / K_{i j}}{1+\sum_{i}\left[S_{i}\right] / K_{i j}}$.

Here, $F_{j}$ describes the uptake of all substrates $S_{i}$ by consumer $E_{j}$. The left-hand side of the inequality is the uptake computed by directly applying Monod kinetics, while the right-hand side is obtained by applying competitive Monod kinetics (e.g., Litchman and Klausmeier, 2008). Inequality (6) is even true when $K_{i j}$ is independent of $i$. Besides being inconsistent with the partition principle, Monod kinetics also violates the non-singular principle, which can be demonstrated by observing that as $\left[E_{j}\right]$ approaches very large values so does $F_{j}$. This linear dependence of $F_{j}$ on $\left[E_{j}\right]$ results in large biases of predicted parametric sensitivities under high ratios of $\left[E_{j}\right]$ with respect to substrates (Schnell and Maini, 2000; Tang and Riley, 2013a; Tang, 2015) and is inconsistent with the non-singularity implied in Eq. (5).

For competitive Monod kinetics on the right-hand side of inequality (6), we may define $K_{j}=[S] /\left(\sum_{i}\left[S_{i}\right] / K_{i j}\right)$ (e.g., Murdoch, 1973), resulting in

$$
F_{j}=\left[E_{j}\right] \frac{k_{2, j}^{+}\left(\sum_{i}\left[S_{i}\right]\right) / K_{j}}{1+\left(\sum_{i}\left[S_{i}\right]\right) / K_{j}}=\left[E_{j}\right] \frac{k_{2, j}^{+}[S] / K_{j}}{1+[S] / K_{j}},
$$


where $[S]=\sum_{i}\left[S_{i}\right]$ designates the total free concentrations of all substrates. Equation (7) therefore carries the same partition principle implied in the first summation in Eq. (4) of the full kinetic formulation, suggesting that competitive Monod kinetics satisfies the partition principle for consistent scaling of substrate-consumer relationships. Nevertheless, because competitive Monod kinetics is linear in $\left[E_{j}\right]$, as is classic Monod kinetics, it still violates the non-singular principle for consistent scaling.

In Tang (2015) (and also in Borghans et al., 1996 and Tang and Riley, 2013a), it was shown that the linear dependence of $F_{j}$ on $\left[E_{j}\right]$, as predicted by Monod kinetics and similarly by competitive Monod kinetics, is due to their failure to impose the substrate mass (or surface area) balance in deriving their mathematical formulations. This problem has been rectified in ECA kinetics (Tang and Riley, 2013a), which was shown to predict much more accurate parametric sensitivity than Monod kinetics when compared with analytical solutions (Tang, 2015). Since the success of all model calibrations relies on the accuracy of modeled response variables' sensitivity to model parameters (e.g., Wang et al., 2001; Williams et al., 2005; Tang and Zhuang, 2009; van Werkhoven et al., 2009; Qian et al., 2015), and plant-microbial competitions of nutrients often occur under high consumer abundances with respect to their substrates (as corroborated by the nitrogen and phosphorus limitations that are commonly observed in natural ecosystems; e.g., Vitousek et al., 2010), developing robust biogeochemical models requires substrate kinetics that gives accurate parametric sensitivities under a wide range of parameter values.

We therefore ask the question: how should we achieve a consistent scaling from the simplest redox reaction $A+$ $B \stackrel{E}{\rightarrow}$ products (i.e., $A B-E$ type) to a network that mixes many redox reactions and even single-substrate Monod-type reactions? Aside from the two criteria (i.e., the partition principle and non-singularity) discussed above, we suggest a third criterion that a consistent scaling of substrate-consumer relationships should seamlessly transition from a singlesubstrate $A-E$ Monod-type reaction to the $A B-E$ type redox reaction without making contradictory assumptions of the parameters in its theoretical derivation.

In the following, we address the above process-scaling question by first presenting the step-by-step derivation of DM kinetics and SU kinetics from the EC formulation of the redox reaction $A+B \stackrel{E}{\rightarrow}$ products. Conceptually, DM kinetics can be viewed as a direct application of chemical kinetics that the reaction rate of substrates $A$ and $B$ with consumer $E$ is determined by the product of $A$ and $B$ 's binding probability to $E$ (which in Monod form is $[A] /\left(K_{A}+[A]\right)$ for substrate $A$, and $[B] /\left(K_{B}+[B]\right)$ for substrate $\left.B\right)$. Kooijman (1998) was the first to derive SU kinetics using queue theory (e.g., Gross et al., 2011), and Brandt et al. (2003) discussed its use for $A B-E$ type redox reactions. The following derivation stresses scaling inconsistencies implied in DM and SU kinet- ics, and we will show that DM kinetics cannot be extended for consistent process scaling of substrate-consumer relationships. We then present SUPECA kinetics, which remedies the inconsistencies in SU kinetics. We demonstrate the benefits of using SUPECA kinetics in terms of numerical accuracy and present a proof-of-concept example by modeling the moisture control of aerobic soil respiration. Finally, we discuss how one can apply SUPECA kinetics to traitbased modeling approaches in various biogeochemical systems (e.g., Bouskill et al., 2012; Follows et al., 2007; Litchman and Klausmeier, 2008).

\section{Derivation of ECA kinetics for $A B-E$ type redox reaction $A+B \stackrel{E}{\rightarrow}$ products}

\subsection{Governing equations}

We schematically represent the enzymatic redox reaction network as

$$
\begin{aligned}
& E+A \underset{k_{A}^{-}}{\stackrel{k_{A}^{+}}{\leftrightarrow}} E A \\
& +\quad+ \\
& B \quad B
\end{aligned}
$$

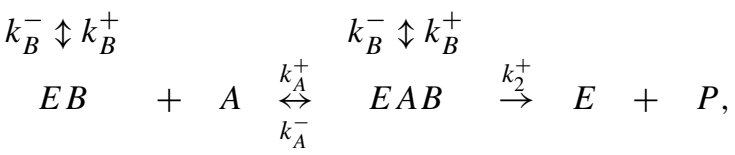

where it is assumed that the order of substrates $A$ and $B$ binding to consumer $E$ does not affect the kinetic coefficients, as is done in most modeling studies (e.g., Yeh et al., 2001).

By law of mass action and the total QSSA (tQSSA; see Borghans et al., 1996; Tang and Riley, 2013a), we have the governing equations (Appendix A):

$$
\begin{aligned}
& \frac{\mathrm{d}[A]_{T}}{\mathrm{~d} t}=-k_{2}^{+}[E A B] \\
& \frac{\mathrm{d}[B]_{T}}{\mathrm{~d} t}=-k_{2}^{+}[E A B] \\
& k_{A}^{+}[E][A]+k_{B}^{-}[E A B]=\left(k_{A}^{-}+k_{B}^{+}[B]\right)[E A] \\
& k_{B}^{+}[E][B]+k_{A}^{-}[E A B]=\left(k_{B}^{-}+k_{A}^{+}[A]\right)[E B] \\
& k_{A}^{+}[E B][A]+k_{B}^{+}[E A][B]=\left(k_{A}^{-}+k_{B}^{-}+k_{2}^{+}\right)[E A B],
\end{aligned}
$$

where

$$
\begin{aligned}
& {[A]_{T}=[A]+[E A]+[E A B]} \\
& {[B]_{T}=[B]+[E B]+[E A B]} \\
& {[B]_{T}=[B]+[E B]+[E A B] .}
\end{aligned}
$$

The derivation of substrate kinetics is therefore equivalent to solving for $[E A B]$ from the EC problem defined by Eqs. (11)-(16). However, because this set of equations is non-linear, and no analytical solutions are available (to our 
knowledge), some linearization is warranted to obtain analytical approximations. As we describe below, linearization with different assumptions can lead to DM, SU, and SUPECA kinetics.

To clarify, we note that obtaining the substrate kinetics only requires solving Eqs. (11)-(16); various production and destruction terms can be added to Eqs. (9) and (10) to form a full dynamic model (e.g., Maggi and Riley, 2009) without affecting our derivation below.

\subsection{Dual Monod kinetics and synthesizing unit kinetics}

One method to linearize Eqs. (11)-(16) is to assume that concentrations of consumer-substrate complexes are so small that free substrate concentrations are effectively equal to bulk concentrations (e.g., for substrate $A:[A]_{T}=[A]$ ). This approach, when combined with different assumptions on the relative magnitudes of kinetic parameters, leads to the popular DM kinetics and the two-substrate SU kinetics.

\subsubsection{Dual Monod kinetics}

We now derive DM kinetics. Adopting the equilibrium approximation that forward binding between consumer and substrate is in rapid equilibrium with backward dissociation of consumer-substrate complex (e.g., Michaelis and Menten, 1913; Pyun, 1971), we have the following:

$$
\begin{aligned}
& {[E A][B]=\frac{k_{B}^{-}}{k_{B}^{+}}[E A B]=K_{B}[E A B]} \\
& {[E B][A]=\frac{k_{A}^{-}}{k_{A}^{+}}[E A B]=K_{A}[E A B],}
\end{aligned}
$$

which then transforms Eqs. (11) and (12) into

$$
\begin{aligned}
& {[E][A]=\frac{k_{A}^{-}}{k_{A}^{+}}[E A]=K_{A}[E A]} \\
& {[E][B]=\frac{k_{B}^{-}}{k_{B}^{+}}[E B]=K_{B}[E B] .}
\end{aligned}
$$

By solving for $[E A B]$ from Eqs. (14)-(16) using Eqs. (17)-(20), we obtain the consumer-substrate complex for DM kinetics (see Appendix B):

$$
\frac{\mathrm{d}[A]_{T}}{\mathrm{~d} t}=-k_{2}^{+}[E]_{T} \frac{[A]}{K_{A}+[A]} \frac{[B]}{K_{B}+[B]} .
$$

As one substrate, e.g., [A], becomes unlimited, Eq. (21) can be reduced to the classical MM kinetics:

$\frac{\mathrm{d}[A]_{T}}{\mathrm{~d} t}=-k_{2}^{+} \frac{[E]_{T}[B]}{K_{B}+[B]}$.

We note that the half-saturation coefficient $K_{B}=k_{B}^{-} / k_{B}^{+}$ in Eq. (22) is different from its usual definition (i.e., $K_{B}=$ $\left.\left(k_{2}^{+}+k_{B}^{-}\right) / k_{B}^{+}\right)$if one derives MM kinetics rigorously starting from a single-substrate and single-consumer system (e.g.,
Tang, 2015). For this reason, we assert that DM kinetics cannot achieve a self-consistent scaling from a one-substrate reaction to multiple-substrate reactions. More specifically, by substituting Eqs. (17) and (18) into Eq. (13), one obtains $k_{2}^{+}=0$, or at least $k_{2}^{+} \ll \max \left(k_{A}^{-}, k_{B}^{-}\right)$, which states that the consumer is very inefficient in processing the substrate. However, MM kinetics does not require the dissociation rate to be much higher than the product generation rate from the consumer-substrate complex, i.e., $k_{2}^{+} \ll \max \left(k_{A}^{-}, k_{B}^{-}\right)$(e.g., Briggs and Haldane, 1925). Nor do the high dissociation rates of $[E A],[E B]$, and $[E A B]$ favor the consumer's assimilation of substrates under usual substrate concentrations (e.g., Van Slyke and Cullen, 1914), even though a high dissociation rate of the enzyme-substrate complexes may possess some theoretical advantage under high substrate concentrations when the consumer is a single enzyme (Reuveni et al., 2014). On the contrary, most existing applications tend to assume $k_{2}^{+} \gg k_{A}^{-}$and $k_{2}^{+} \gg k_{B}^{-}$(e.g., Holling, 1959, 1966; Aksnes and Egge, 1991; Armstrong, 2008; Bonachela et al., 2011), such that $K_{B} \approx k_{2}^{+} / k_{B}^{+}$for MM kinetics and $r-K$ selection can be explained by linking $k_{2}^{+}$with growth rate, and $k_{A}^{+}$and $k_{B}^{+}$with substrate competitive ability (e.g., Litchman and Klausmeier, 2008). Therefore, for biogeochemical modeling, DM and MM (or Monod) kinetics are based on different assumptions of the relative magnitudes of kinetic parameters, and no smooth transition from single- (MM) to multi-substrate (DM) kinetics exists.

\subsubsection{Synthesizing unit kinetics}

In deriving SU kinetics for the redox reaction network represented in Eq. (8), consumer $E$ is viewed as a generalized enzyme that generates bioproducts by processing substrates $A$ and $B$. SU computes the specific reaction rate per unit concentration of $E$ as the product generation rate $k_{2}^{+}$times the probability that $E$ binds with both substrates $A$ and $B$ (which is $\left.[E A B] /[E]_{T}\right)$. SU kinetics requires the sufficient flux condition $k_{A}^{+}[A] \gg k_{B}^{-}$and $k_{B}^{+}[B] \gg k_{A}^{-}$(Kooijman, 2010). Defining $\widetilde{k}_{2}^{+}=k_{A}^{-}+k_{B}^{-}+k_{2}^{+}$, Eqs. (11)-(13) become

$k_{A}^{+}[E][A]=k_{B}^{+}[B][E A]$

$k_{B}^{+}[E][B]=k_{A}^{+}[A][E B]$

$k_{A}^{+}[E B][A]+k_{B}^{+}[E A][B]=\widetilde{k}_{2}^{+}[E A B]$.

From Eqs. (23)-(25), we obtain (see Appendix C)

$$
\frac{\mathrm{d}[A]_{T}}{\mathrm{~d} t}=-\frac{k_{2}^{+}[E]_{T} / \tilde{k}_{2}^{+}}{\frac{1}{k_{2}^{+}}+\frac{1}{k_{A}^{+}[A]}+\frac{1}{k_{B}^{+}[B]}-\frac{1}{k_{A}^{+}[A]+k_{B}^{+}[B]}} .
$$

The two-substrate SU kinetics (Eq. 26) can also be viewed as a special case of the general SU kinetics for any number of complementary substrates, which was first derived by Kooijman (1998) based on queue theory (e.g., Gross et al., 2011). Kooijman (1998) assumed that consumers act like synthesizing units, which process substrates in two steps: binding 
and production. He then assumed that all flux rates (including production rates $k_{2}^{+}$and substrate-binding rates $k_{A}^{+}[A]$ and $\left.k_{B}^{+}[B]\right)$ are of Poisson distributions, and calculated the overall specific substrate consumption rate as the reciprocal of the expected total processing time (i.e., the denominator of Eq. 26). The last term in the denominator of Eq. (26) comes from the assumption of parallel binding of substrates $A$ and $B$ to $E$, which disappears if sequential binding is assumed (e.g., Brandt et al., 2003).

As one substrate, e.g., A, becomes unlimited, singlesubstrate Monod kinetics is recovered from Eq. (26):

$$
\frac{\mathrm{d}[A]_{T}}{\mathrm{~d} t}=-\frac{k_{2}^{+}[E]_{T}}{1+\frac{\widetilde{k}_{2}^{+}}{k_{B}^{+}[B]}}=-\frac{k_{2}^{+}[E]_{T}[B]}{\frac{\widetilde{k}_{2}^{+}}{k_{B}^{+}}+[B]},
$$

which has a half-saturation coefficient similar to what would be derived for a single-substrate, single-consumer reaction (e.g., Tang, 2015). By assuming Poisson distribution of the kinetic parameters, it can also be shown for a single enzyme molecule that MM kinetics represents the statistical mean of the fluctuating activity of the enzyme (English et al., 2006; Reuveni et al., 2014). That kinetics of both single-substrate reactions and two-substrate redox reactions can be similarly derived using statistical theory and that Eqs. (26) and (27) can be obtained from the EC formulation using consistent assumptions of the relative magnitudes of kinetic parameters indicates, in contrast to DM kinetics, that SU kinetics is able to scale consistently between one- and two-substrate redox reactions.

\subsection{SUPECA kinetics}

In Tang and Riley (2013a) and Tang (2015), it was shown that the derivation of MM kinetics ignores the substrate mass balance constraint, resulting in MM kinetics predicting inaccurate parametric sensitivity over the wide range of substrate to consumer ratios (e.g., Fig. 1 in Tang, 2015). This problem is particularly acute when consumer abundances are high with respect to their substrates, a situation that may occur in in vivo conditions (Sols and Marco, 1970; Schnell and Maini, 2000) or when consumers interact with mineral surfaces, such as microbial decomposition of soil organic matter or plant-microbial competition for soil nutrients (Schimel and Bennett, 2004; Vitousek et al., 2010; Resat et al., 2012; Tang and Riley, 2015; Zhu et al., 2016a). In the above, we also note that the substrates' mass balance constraints (Eqs. 14 and 15) are not used in deriving DM and SU kinetics, suggesting that both DM and SU kinetics may suffer from the same deficiency as MM kinetics. Further, since DM kinetics fails to consistently scale from one to two substrates, we focus below on combining SU and ECA kinetics into SUPECA kinetics to achieve a scalable and non-singular formulation of redox reactions.

As implied in Eqs. (9)-(16), the derivation of substrate kinetics requires solving for $[E A B]$ from non-linear Eqs. (11)-
(16), whose analytical solutions are not available. To obtain improved solutions as compared to SU kinetics, we applied a first-order closure approach (Appendix D) which is the perturbation method truncated to first-order accuracy that describes the first-order term using appropriate mean states (e.g., Shankar, 1994; Tang et al., 2007) to the system formed by Eqs. (11)-(16), leading to SUPECA kinetics:

$$
\begin{aligned}
\frac{\mathrm{d}[A]_{T}}{\mathrm{~d} t} & =-\frac{[E]_{T}}{\frac{1}{k_{2}^{+}} \frac{\bar{f}_{A} \bar{f}_{B} f_{A B}}{f_{A} f_{B} \bar{f}_{A B}}+\frac{1}{f_{A}}+\frac{1}{f_{B}}-\frac{f_{A} \bar{f}_{B}+\bar{f}_{A} f_{B}-\bar{f}_{A} \bar{f}_{B}}{f_{A} f_{B} \bar{f}_{A B}}}, \\
=- & \frac{k_{2}^{+}[E]_{T}\left(f_{A} / k_{2}^{+}\right)\left(f_{B} / k_{2}^{+}\right)}{\frac{\bar{f}_{A} \bar{f}_{B}}{k_{2}^{+} \bar{f}_{A B}} \frac{f_{A B}}{k_{2}^{+}}+\frac{f_{A B}}{k_{2}^{+}}-\frac{f_{A} \bar{f}_{B}+\bar{f}_{A} f_{B}-\bar{f}_{A} \bar{f}_{B}}{k_{2}^{+} \bar{f}_{A B}}}
\end{aligned}
$$

where $f_{A}=k_{A}^{+}[A]_{T}, \quad f_{B}=k_{B}^{+}[B]_{T}, \quad \bar{f}_{A}=f_{A}+k_{A}^{+}[E]_{T}$, $\bar{f}_{B}=f_{B}+k_{B}^{+}[E]_{T}, f_{A B}=f_{A}+f_{B}$, and $\bar{f}_{A B}=\bar{f}_{A}+\bar{f}_{B}$. In Eq. (28), we assumed $k_{2}^{+} \gg k_{A}^{-}$and $k_{2}^{+} \gg k_{B}^{-}$, so that $k_{2}^{+} \approx$ $\tilde{k}_{2}^{+}$(this relationship will be used throughout the remainder of this paper). It can then be verified that if $[E]_{T} \ll[A]_{T}$ and $[E]_{T} \ll[B]_{T}$, SUPECA kinetics as represented in Eq. (28) becomes SU kinetics in Eq. (26). Further, if one of the two substrates, say $[B]_{T}$, becomes unlimited, Eq. (28) is reduced to

$\frac{\mathrm{d}[A]_{T}}{\mathrm{~d} t}=-\frac{[E]_{T}}{\frac{1}{k_{2}^{+}} \frac{\bar{f}_{A}}{f_{A}}+\frac{1}{f_{A}}}=-\frac{f_{A}[E]_{T}}{1+\frac{\bar{f}_{A}}{k_{2}^{+}}}$,

which, by using the definition of $f_{A}$ and $\bar{f}_{A}$, becomes the single-substrate ECA kinetics equation (Tang, 2015).

\section{SUPECA kinetics for a network of reactions}

In actual biogeochemical systems, it is more common for many substrates to be processed by many consumers concurrently (and such an assumption is implicitly assumed in the space-time-process unit of any biogeochemical model). To consistently handle such situations, Tang and Riley (2013a) derived ECA kinetics (see Fig. 1 for a graphic demonstration) for calculating the consumption of a substrate $S_{i}$ by a consumer $E_{j}$ in a network of single-substrate reactions $A \stackrel{E}{\rightarrow}$ products:

$$
\frac{\mathrm{d}\left[S_{i}\right]_{T, j}}{\mathrm{~d} t}=-\frac{k_{2, i j}^{+}\left[E_{j}\right]_{T}\left(\left[S_{i}\right]_{T} / K_{i j}\right)}{1+\sum_{l=1}^{l=I}\left(\left[S_{l}\right]_{T} / K_{l j}\right)+\sum_{l=1}^{l=J}\left(\left[E_{l}\right]_{T} / K_{i l}\right)} .
$$

By defining the normalized substrate flux (with subscript "c" designating that the summation is over a column of the graph in Fig. 1),

$F_{\mathrm{c}, j}=\sum_{l=1}^{l=I}\left(\left[S_{l}\right]_{T} / K_{l j}\right)=\sum_{l=1}^{l=I} F_{\mathrm{c}, j}^{\{l\}}$ 


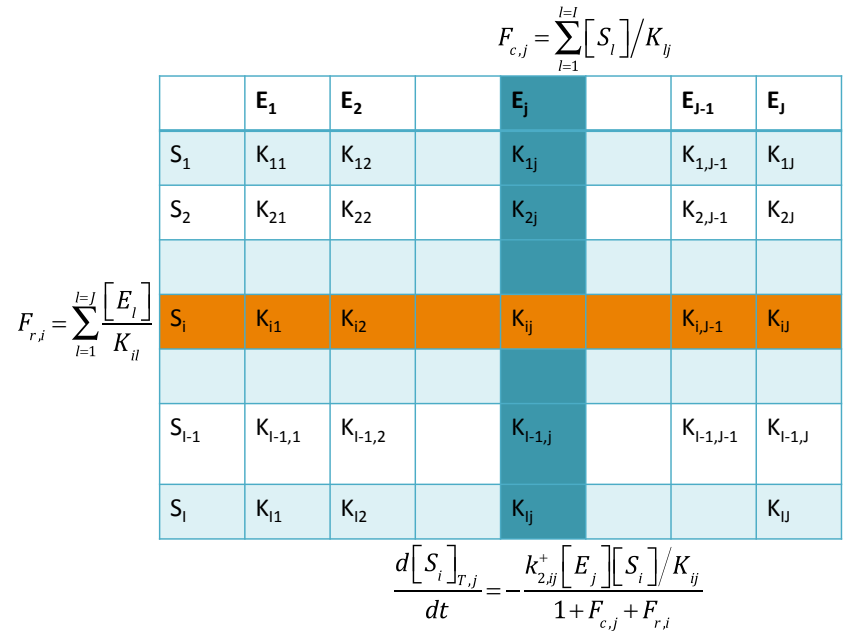

Figure 1. Graphical representation of ECA kinetics as derived in Tang and Riley (2013a). The equation below the table shows the uptake of substrate $S_{i}$ by consumer $E_{j}$ as a function the normalized substrate flux $F_{\mathrm{c}, j}$ and its conjugate flux $F_{\mathrm{r}, i}$. Subscript "c" designates column, and " $\mathrm{r}$ " designates row. When $K_{i j}$ is very large compared to other entries in the matrix, the interaction between substrate $S_{i}$ and consumer $E_{j}$ can be ignored.

and its conjugate (with subscript " $\mathrm{r}$ " designating that the summation is over a row of the graph in Fig. 1),

$F_{\mathrm{r}, i}=\sum_{l=1}^{l=J}\left(\left[E_{l}\right]_{T} / K_{i l}\right)=\sum_{l=1}^{l=J} F_{\mathrm{r}, i}^{\{l\}}$.

Equation (30) can then be rewritten as

$$
\begin{aligned}
\frac{\mathrm{d}\left[S_{i}\right]_{T, j}}{\mathrm{~d} t} & =-k_{2, i j}^{+}\left[E_{j}\right]_{T}\left(\frac{F_{\mathrm{c}, j}^{\{i\}}}{1+F_{\mathrm{r}, i}+F_{\mathrm{c}, j}}\right) \\
& =-k_{2, i j}^{+}\left[S_{i}\right]_{T}\left(\frac{F_{\mathrm{r}, i}^{\{j\}}}{1+F_{\mathrm{r}, i}+F_{\mathrm{c}, j}}\right) .
\end{aligned}
$$

The normalized substrate flux as defined in Eq. (31) and its conjugate in Eq. (32) implies that the consumption of substrate $S_{i}$ by consumer $E_{j}$ as described by ECA kinetics in Eq. (33) may be interpreted as either (i) the potential substrate processing rate of $E_{j}$ (i.e., $k_{2, i j}^{+}\left[E_{j}\right]$ ) weighted by the relevant importance of the reaction pathway $S_{i} \stackrel{E_{j}}{\rightarrow}$ products (i.e., $F_{\mathrm{c}, j}^{\{i\}}$ ) under the influence of all competing substrate fluxes $F_{\mathrm{c}, j}^{\{l\}}$ (towards consumer $E_{j}$ ) and all competing agents' demands $F_{\mathrm{r}, i}^{\{l\}}$ (towards substrate $S_{i}$ ) or (ii) the linear decay potential of $S_{i}$ (i.e., $k_{2, i j}^{+}\left[S_{i}\right]_{T}$ ) weighted by the relevant importance of $F_{\mathrm{r}, i}^{\{j\}}$ under the influence of all competing substrate fluxes and competing agents' demands.

We note that Eqs. (31) and (32) define some very interesting scaling relationships. For instance, from Eq. (31), we can define the effective substrate affinity for the bulk substrates $\left([\bar{S}]_{T}\right.$, defined as the total of all substrates) that are accessible for consumer $E_{j}$ as

$$
K_{E, j}=\left(\sum_{l=1}^{l=I}\left[S_{l}\right]_{T}\right) / F_{\mathrm{c}, j}=[\bar{S}]_{T} / F_{\mathrm{c}, j} .
$$

Similarly, we can define the effective affinity for substrate $S_{i}$ resulting from all competing agents as

$$
K_{S, i}=\left(\sum_{l=1}^{l=J}\left[E_{l}\right]_{T}\right) / F_{\mathrm{r}, i}=[\bar{E}]_{T} / F_{\mathrm{r}, i} .
$$

Then, by substituting Eqs. (34) and (35) into Eq. (33), we obtain

$$
\begin{aligned}
\frac{\mathrm{d}\left[S_{i}\right]_{T, j}}{\mathrm{~d} t} & =-\frac{k_{2, i j}^{+}\left[E_{j}\right]_{T}\left([\bar{S}]_{T} / K_{E, j}\right)}{1+[\bar{S}]_{T} / K_{E, j}+[\bar{E}]_{T} / K_{S, i}} \frac{F_{\mathrm{c}, j}^{\{i\}}}{F_{\mathrm{c}, j}}, \\
= & -\frac{k_{2, i j}^{+}\left[S_{i}\right]_{T}\left([\bar{E}]_{T} / K_{S, i}\right)}{1+[\bar{S}]_{T} / K_{E, j}+[\bar{E}]_{T} / K_{S, i}} \frac{F_{\mathrm{r}, i}^{\{j\}}}{F_{\mathrm{r}, i}},
\end{aligned}
$$

which again shows the linear partition in terms of $F_{\mathrm{c}, j}^{\{i\}} / F_{\mathrm{c}, j}$ and $F_{\mathrm{r}, i}^{\{j\}} / F_{\mathrm{r}, i}$.

By applying the above two scaling relationships and the three consistent scaling criteria (as we proposed in the introduction section) to SUPECA kinetics in Eq. (28), we obtain (in Appendix E) the network form of SUPECA kinetics:

$\frac{\mathrm{d}\left[A_{i}\right]_{T, j k}}{\mathrm{~d} t}=$

$-\frac{k_{2, i j k}^{+}\left[E_{k}\right]_{T} F_{\mathrm{c}, A, k}^{\{i\}} F_{\mathrm{c}, B, k}^{\{j\}}}{\frac{G_{A, i k} G_{B, j k}}{G_{A B, i j k}} F_{\mathrm{c}, A B, k}+F_{\mathrm{c}, A B, k}-\frac{F_{\mathrm{c}, A, k} G_{B, j k}+G_{A, i k} F_{\mathrm{c}, B, k}-G_{A, i k} G_{B, j k}}{G_{A B, i j k}}}$,

where

$$
\begin{aligned}
& F_{\mathrm{c}, A, k}=\sum_{l} F_{\mathrm{c}, A, k}^{\{l\}}=\sum_{l}\left[A_{l}\right]_{T} / K_{A, l k} \\
& F_{\mathrm{c}, B, k}=\sum_{l} F_{\mathrm{c}, B, k}^{\{l\}}=\sum_{l}\left[B_{l}\right]_{T} / K_{B, l k} \\
& F_{\mathrm{c}, A B, k}=F_{\mathrm{c}, A, k}+F_{\mathrm{c}, B, k} \\
& F_{r, A, i}=\sum_{l}\left[E_{l}\right]_{T} / K_{A, i l} \\
& F_{r, B, j}=\sum_{l}\left[E_{l}\right]_{T} / K_{B, j l} \\
& G_{A, i k}=F_{\mathrm{c}, A, k}+F_{r, A, i} \\
& G_{B, j k}=F_{\mathrm{c}, B, k}+F_{r, B, j} \\
& G_{A B, i j k}=G_{A, i k}+G_{B, j k} .
\end{aligned}
$$

For Eq. (37), one can verify that if $F_{\mathrm{c}, B, k}$ (or $F_{\mathrm{c}, A, k}$ ) goes to very large values, SUPECA kinetics is reduced to ECA kinetics (Eq. 33). Therefore, SUPECA kinetics as formulated in Eq. (37) is an extension of SU and ECA kinetics, and 


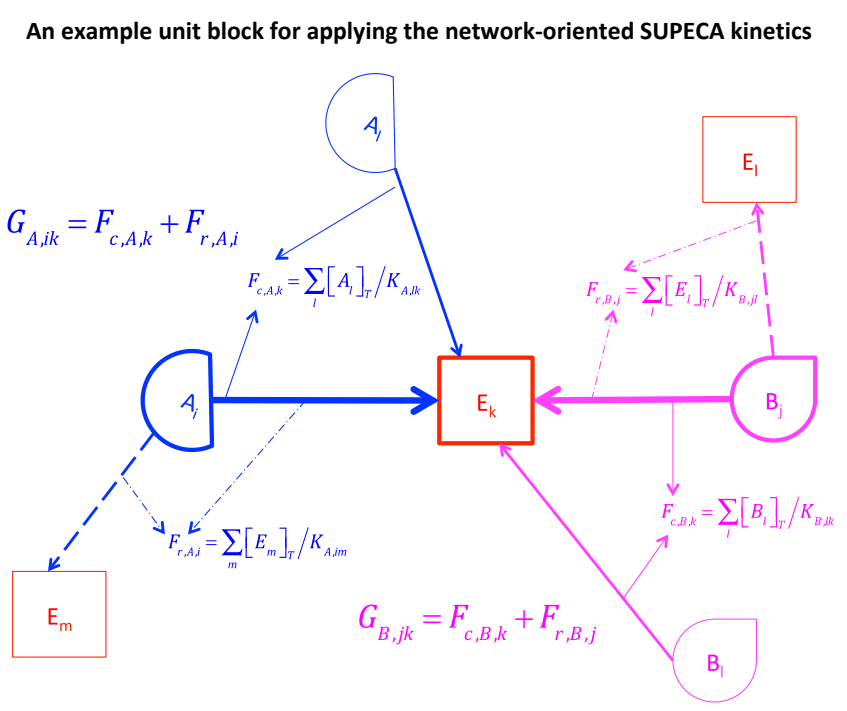

Figure 2. Graphic representation for the relationships between substrates, consumers, and normalized fluxes and their conjugates for a block unit of a large substrate-consumer network.

SUPECA is applicable for consistent scaling of substrateconsumer networks involving both single-substrate reactions and redox reactions (a visual demonstration of SUPECA kinetics is in Fig. 2).

\section{Numerical accuracy of SUPECA kinetics}

Following Tang and Riley (2013a), we assume that the EC formulation is a good approximation to the law of mass action and use it to evaluate the numerical accuracy of SUPECA kinetics. Because of numerical complexity, we restricted the comparison to the $A B-E$ problem as formulated by Eqs. (11)-(16) with the assumption of $k_{A}^{-}=k_{B}^{-}=0$ and included a substrate sorbent to mimic a class of biogeochemistry problems in soil, such as aerobic soil ammonium nitrification and aerobic soil organic carbon decomposition (formulated in Appendix F; a graphic representation is available in the Supplement).

We evaluated the numerical accuracy of SUPECA (Eq. 37) and SU (Eq. 26) over a wide range of parameter values. We fixed both substrates at a nominal value of $40 \mathrm{~mol} \mathrm{~m}^{-3}$, and $k_{2}^{+}$, the maximum substrate processing rate at $48 \mathrm{~s}^{-1}$. Then we sampled the affinity parameters exponentially over the range $[0,1000] \mathrm{mol} \mathrm{m}^{-3}$ and the microbe and sorbent concentrations uniformly over the range $[0,1000] \mathrm{mol} \mathrm{m}^{-3}$. Using a total of 1000 sets of randomly paired parameters, we compared how close SUPECA and SU approximations are to the EC solution in terms of root mean square error (RMSE) and goodness of linear fit. Because SU kinetics does not allow a direct integration of the Langmuir adsorption into the calculation of microbe-substrate complexes, we followed Resat et al. (2012) and first solved the Langmuir isotherm
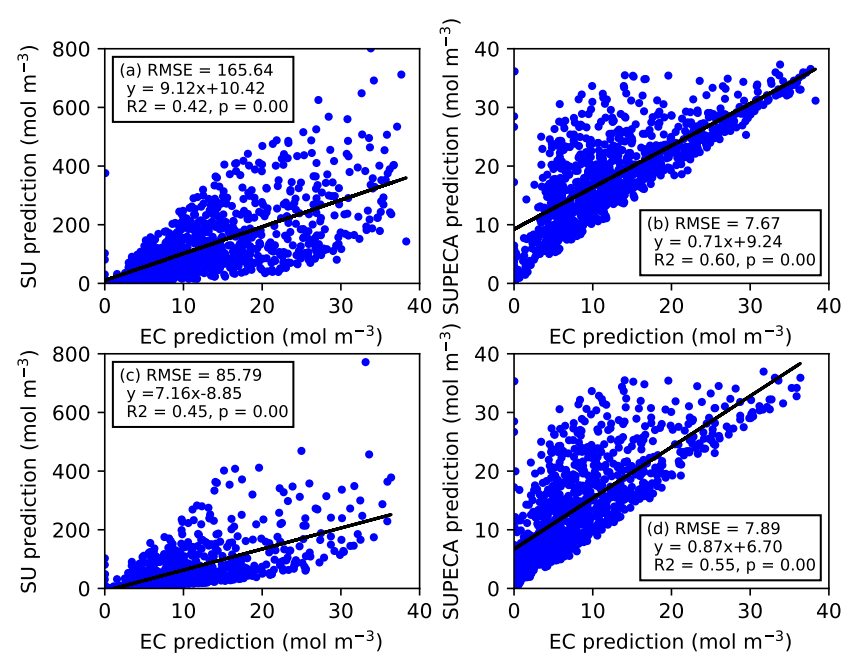

Figure 3. Benchmark of the SU (left column) and SUPECA (right column) predictions against those by the full EC formulation. We note that the $y$ axes of the left panels are of much larger scale than those on the right. The problem is formulated in Appendix F. Panels (a) and (b) are for the case when $M=0$; panels (c) and (d) are for uniformly distributed $M>0$. The black solid lines are the linear regression of SU or SUPECA predictions with respect to the EC solution, whose statistics are shown in the figure. The related distributions of parameters are in Fig. S1 of the Supplement.

to obtain the free substrate concentrations and then entered these free substrate concentrations into SU to obtain the microbe-substrate complex. This artificial ordering in calculation (as needed by the SU approach) suggests that the SU implementation may lead to significant numerical errors (similar numerical difficulties are associated with the popular MM kinetics; Resat et al., 2012; Tang and Riley, 2013a).

Our comparison (Figs. 3 and 4) indicates that SUPECA kinetics is superior to SU kinetics in computing the microbesubstrate complex in the presence of substrate binding competition between microbes and sorbent. SUPECA predictions are more accurate than SU predictions in terms of goodness of linear fitting and RMSE (for which the linear regressions are shown as black solid lines in Fig. 3). In magnitude, the RMSEs of SUPECA predictions are less than $10 \%$ of that of $\mathrm{SU}$ predictions (and also note that the $y$-axis ranges for $\mathrm{SU}$ predictions are 20 times of those for SUPECA predictions). The slope of linear fitting from SUPECA predictions is also much closer to the ideal value 1.0, whereas that from SU predictions is far greater than 1.0, suggesting that SU kinetics significantly overestimates microbe-substrate complexes under a wide range of conditions. When the model predictions are evaluated as a function of the relative abundances of consumers and substrates (Fig. 4), SU overestimates are found under high ratios of consumer abundances with respect to substrates (Fig. 4a, c). In contrast, SUPECA predictions agree well with EC predictions over the whole range of relative abundances (Fig. 4b, d). This very large overestimation 

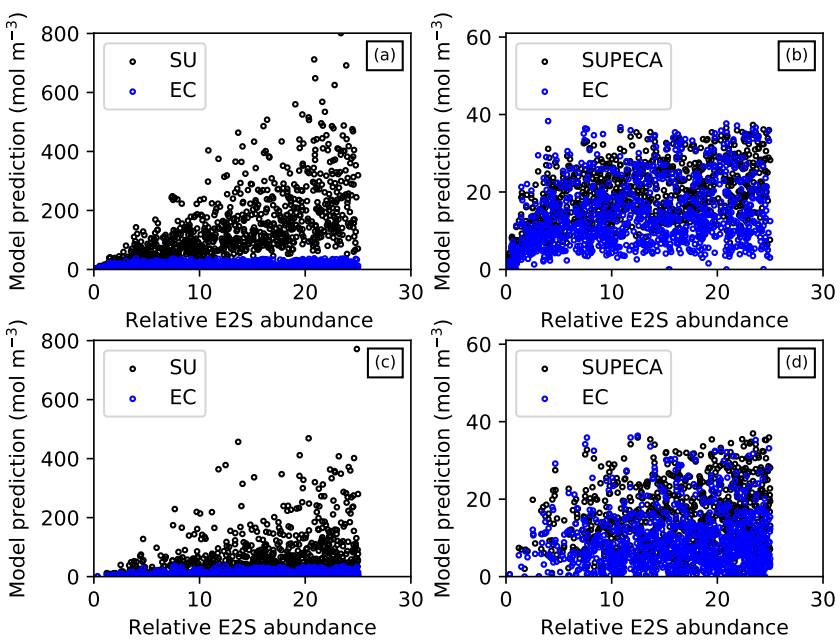

Figure 4. Model predicted consumer-substrate complexes as a function of the relative abundance of consumers with respect to substrates. Corresponding to Fig. 3, panels (a) and (b) are for the case when $M=0$; panels (c) and (d) are for uniformly distributed $M>0$.

by SU calculations is explained by the linear dependence of the consumer-substrate complexes on microbial abundances in deriving SU kinetics (Eq. 26). Therefore, combined with the better numerical performance of ECA (Tang and Riley, 2013a; Tang, 2015) than MM kinetics, we contend that SUPECA kinetics is numerically more convenient and more accurate than SU kinetics in calculating the microbe-substrate complexes for situations involving microbes, enzymes, substrates, and soil minerals (e.g., Tang and Riley, 2015). In particular, because nutrient limitations tend to occur under high relative consumer abundances with respect to their substrates, the larger prediction bias of SU than SUPECA suggests that SUPECA should be preferred for soil biogeochemical modeling. However, for applications to real problems, the validity of SUPECA kinetics depends on the EC formulation and the tQSSA, and there are situations where even the EC formulation might fail (e.g., Maggi and Riley, 2009; Pedersen et al., 2008).

\section{Example application to modeling aerobic heterotrophic respiration}

As a proof-of-concept example, we applied SUPECA kinetics to predict the moisture stress on aerobic soil respiration. We note that we are not suggesting that SUPECA kinetics should replace existing soil biogeochemical (BGC) models, but rather that mechanistic analysis using a SUPECA-based model can inform process understanding and thereby improve such models. Following the CENTURY-like models' approach in modeling topsoil soil carbon dynamics (Coleman and Jenkinson, 1999; Parton and Rasmussen, 1994) and

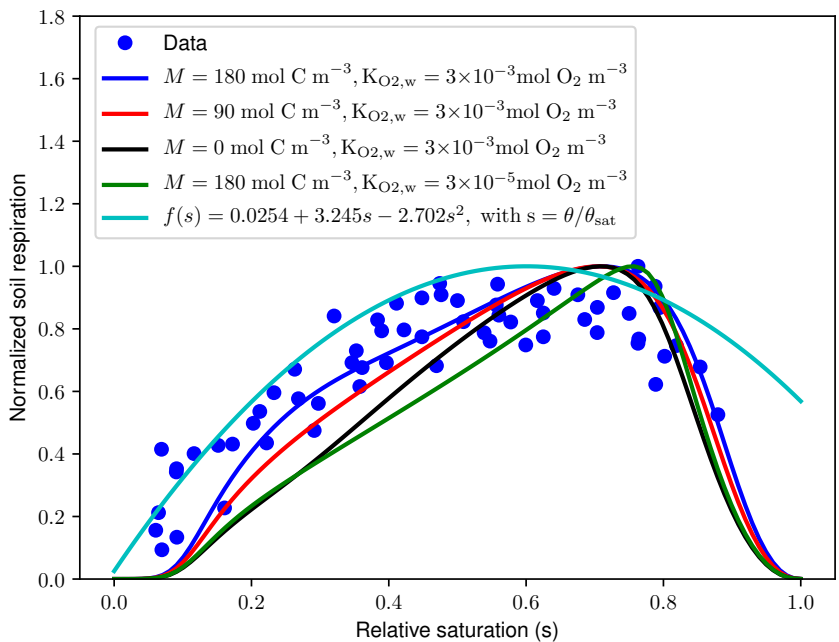

Figure 5. Comparison of predicted normalized soil moisture response functions to that derived from incubation data from Franzluebbers (1999). All response functions are normalized with their respective peak respiration. The $R^{2}$ coefficients of determination for the different response function curves from top to bottom are, respectively, $0.82,0.81,0.77,0.71$, and 0.84 . Note that the curve of $f(s)$ has been normalized to set its maximum value at 1 , making it slightly above the majority of the data points.

the set up of Franzluebbers' (1999) soil incubation experiments (from which the data were used for our model evaluation), this example (Appendix G) considers a homogenous $10 \mathrm{~cm}$ thick topsoil with $2.0 \mathrm{~mol} \mathrm{C} \mathrm{m}^{-3}$ microbes and $3.0 \mathrm{~mol} \mathrm{C} \mathrm{m}^{-3}$ DOC (i.e., dissolvable organic carbon; different DOC values affected our results negligibly as long as they were larger than $0.5 \mathrm{~mol} \mathrm{C} \mathrm{m}^{-3}$ ). We conceptualize transport of substrates (i.e., oxygen and DOC) in soil as a two-stage diffusion process (e.g., Grant, 1991) with the first stage from the bulk soil matrix to the water film covering the microbial microsites and the second stage from the water film to the microbial transporters where substrates are processed. The diffusion processes in soil are calculated based on soil moisture status and the hydraulic properties of a hypothesized soil with a texture of $40 \%$ clay and $30 \%$ sand. The pedotransfer functions used for calculating soil hydraulic properties are from CLM4.5 (Oleson et al., 2013).

Our approach assumes that the inter-microsite (or aggregate) transport dominates intra-aggregate transport, consistent with pore-scale simulations (Yang et al., 2014). The model is solved to steady state by assuming that the microbes, atmospheric oxygen, and DOC are in balance under the influence of Langmuir-type DOC sorption by soil minerals. Calculations are conducted for three levels of soil minerals (with adsorption capacities at 0,90 , and $180 \mathrm{~mol} \mathrm{C} \mathrm{m}^{-3}$ ) and two levels of microbial oxygen affinity (with default $K_{\mathrm{O}_{2} \text {,w }}=3 \times 10^{-5} \mathrm{~mol} \mathrm{~m}^{-3}$ and elevated $K_{\mathrm{O}_{2}, \mathrm{w}}=3 \times 10^{-3} \mathrm{~mol} \mathrm{~m}^{-3}$; Figs. 5 and 6 ). 


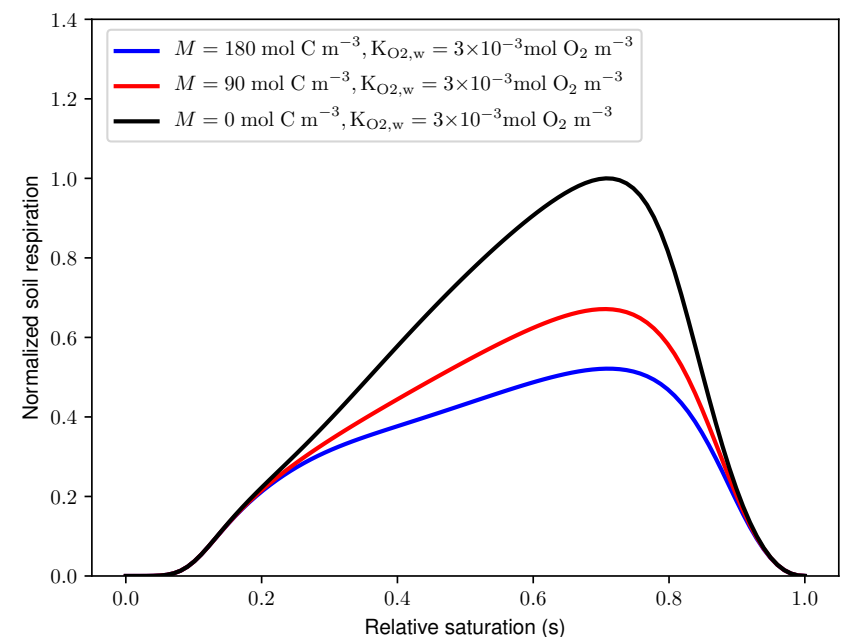

Figure 6. Simulated moisture response functions using elevated affinity parameter for $\mathrm{O}_{2}$. The respiration data are normalized with the peak value from the case with zero soil minerals (i.e., black line in the figure).

The calculation with elevated $K_{\mathrm{O}_{2} \text {,w }}$ (compared to the default $K_{\mathrm{O}_{2} \text {,w }}$ ) indicates the effect of soil aggregates on moisture control of decomposition (see also Appendix G). We evaluated (1) how close our predicted moisture response function is to incubation data from Franzluebbers (1999) and (2) how soil mineral DOC adsorption would affect the soil moisture response function. We also tested a widely used response function approach (e.g., Sierra et al., 2015) for comparison.

When the respiration curves are normalized, we found that all curves have the same pattern where soil respiration first increases from dry soil with increasing moisture and then levels off after reaching a peak value (where the respiration is co-limited by oxygen and DOC bioavailability). The curve with the highest mineral soil carbon adsorption capacity $\left(180 \mathrm{~mol} \mathrm{C} \mathrm{m}^{-3}\right)$ and elevated $K_{\mathrm{O}_{2} \text {,w }}$ value best approximates the incubation data from Franzluebbers (1999). As the sorption capacity becomes smaller, the moisture response function becomes sharper.

When the oxygen affinity parameter is reduced to its default value (while keeping the adsorption capacity at $180 \mathrm{~mol} \mathrm{C} \mathrm{m}^{-3}$; see explanation in Appendix G), the soil moisture response function becomes the sharpest with the highest threshold moisture where the respiration peaks (see green line in Fig. 5). Unlike Kausch and Pallud (2013) and Yang et al. (2014), we have not explicitly simulated the oxygen distribution inside the aggregates. Since the apparent oxygen affinity parameter (which we use here) generally increases with aggregate size (Griffin, 1968), the poorer agreement between data and predictions using the default oxygen affinity parameter indicates that soil aggregates may play an important role in controlling microbes' response to soil moisture stress. Indeed, Franzluebbers (1999) indicated in his Fig. 1 that there are many aggregates in his incubated soil. Moreover, the higher moisture threshold (where respiration peaks) with the default apparent oxygen affinity parameter is consistent with measurements that aggregates may facilitate anaerobic processes under well-ventilated conditions (by increasing the range of soil moisture conditions where oxygen limits aerobic processes; Renault and Stengel, 1994; Keiluweit et al., 2016).

When the moisture response function is evaluated, we found a higher $R^{2}(0.84)$ than those predicted from SUPECA-based methods, which (from top to bottom as in the legends) are $0.82,0.81,0.77$, and 0.71 for the blue, red, black, and green lines, respectively. However, the response function approach overestimated the observed aerobic soil respiration rate at high soil moisture contents. This example illustrates that a higher overall $R^{2}$ from the empirical response function can mask an important feature of soil respiration's dependence on soil moisture.

Higher adsorption capacity resulted in significantly lower soil respiration (Fig. 6), consistent with results for temperature sensitivity described in Tang and Riley (2015). Combining results from Figs. 5 and 6, we conclude that because the soil moisture response function emerges from interactions between biotic and abiotic factors that co-regulate soil organic carbon decomposition (Manzoni et al., 2016), its functional shape is not deterministic. This result contradicts the popular approach used in many soil BGC models (including our own, e.g., Koven et al., 2013; Tang et al., 2013; and others, e.g., Sierra et al., 2015), where a deterministic soil moisture response function is applied to the moisture-unstressed decomposition rate. We also note that there are many different functional forms for the soil moisture response function used in soil BGC models (Sierra et al., 2015).

At the default oxygen affinity value $(3 \times$ $10^{-5} \mathrm{~mol} \mathrm{O}_{2} \mathrm{~m}^{-3}$ ), the derived soil moisture response function is essentially insensitive to mineral soil carbon adsorption capacity (not shown). Since the oxygen affinity parameter reflects the impacts of aggregates, these results demonstrate how soil aggregates may influence soil carbon decomposition rates, an insight that cannot be obtained by fitting response functions to a single dataset.

\section{Potential applications of SUPECA kinetics for trait-based biogeochemical modeling}

Besides the example application above, SUPECA kinetics could be a powerful tool for trait-based modeling in various biogeochemical systems (e.g., Follows et al., 2007; Bouskill et al., 2012; Litchman and Klausmeier, 2008; Merico et al., 2009). As we show above and below, SUPECA kinetics will enable more robust predictions with better numerical consistency and smaller parametric sensitivities than the popular family of Monod kinetics, and SUPECA will be applicable for any biogeochemical system that involves substrate- 
consumer binding and binding competition (of the $A B-E$ or $A-E$ type).

The assertion of smaller parametric sensitivity as predicted by SUPECA (than by Monod kinetics) can be verified using the single-substrate reaction network as an example. In this case, SUPECA is reduced to ECA kinetics, and for some substrate $S_{i}$ in the reaction network, ECA kinetics predicts the sensitivity of its consumption by consumer $\left[E_{j}\right]$ with respect to the maximum processing rate $k_{2, i j}^{+}$as

$$
\left|\frac{\partial}{\partial k_{2, i j}^{+}}\left(\frac{\mathrm{d}\left[S_{i}\right]_{T, j}}{\mathrm{~d} t}\right)\right|=\frac{\left[E_{j}\right]_{T} F_{\mathrm{c}, j}^{\{i\}}}{1+F_{\mathrm{r}, i}+F_{\mathrm{c}, j}}<\frac{\left[E_{j}\right]_{T} F_{\mathrm{c}, j}^{\{i\}}}{1+F_{\mathrm{c}, j}}<\frac{\left[E_{j}\right]_{T} F_{\mathrm{c}, j}^{\{i\}}}{1+F_{\mathrm{c}, j}^{\{i\}}},
$$

where the term after the first " $<$ " is prediction by competitive Monod kinetics and that after the second " $<$ " is by Monod kinetics, suggesting that models using Monod kinetics for substrate competition are more sensitive to parameters and therefore more difficult to calibrate (e.g., Tang and Riley, 2013a).

To quantitatively evaluate our assertion that SUPECA kinetics predicts lower parametric sensitivity, we applied Eq. (46) to 100 competing substrate fluxes of equal magnitude. We then have $F_{\mathrm{c}, j}=100 F_{\mathrm{c}, j}^{\{i\}}$. Meanwhile, if $F_{\mathrm{c}, j}^{\{i\}}>1$, then the sensitivity predicted by competitive Monod kinetics is less than $1 \%$ of that by Monod kinetics. Further, if the competing efforts from all agents are comparable to the overall substrate fluxes, i.e., $F_{\mathrm{r}, i} \approx F_{\mathrm{c}, j}$, then the parametric sensitivity predicted by ECA is about $50 \%$ of that by competitive Monod kinetics. Therefore, ECA (and by extension, SUPECA) prediction is much less sensitive with respect to $k_{2, i j}^{+}$than that by competitive Monod kinetics and Monod kinetics. Moreover, with Eqs. (30) and (37), one can verify that the more substrates and consumers are represented in the system, the smaller the resulting sensitivity predicted by ECA (and SUPECA) kinetics for each $k_{2, i j}^{+}$. One can also verify lower SUPECA uncertainty for other parameters, including substrates and consumer abundances. That including more substrates and consumers will lead to more robust model predictions is a premise underlying trait-based modeling (e.g., Follows et al., 2007; Bouskill et al., 2012), and SUPECA kinetics explicitly integrates this presumption in its formulation.

The assertion of wide applicability with SUPECA kinetics has been demonstrated by a number of successful applications that we have published with ECA kinetics. In a series of studies (Zhu and Riley, 2015; Zhu et al., 2016a, b, 2017), we showed that ECA kinetics significantly improved the modeling of nutrient competition between plants, microbes, and mineral soils. In Tang and Riley (2013a), where ECA kinetics was first proposed, lignin decomposition dynamics were accurately captured without a priori imposing a target lignocellulose index. In Tang and Riley (2013a, 2015) and this study, ECA kinetics was able to seamlessly incorporate Langmuirtype substrate adsorption without invoking an ad hoc numer- ical order that is prerequisite to MM (or Monod) kinetics for modeling mineral, microbe, and substrate interactions.

Finally, we expect SUPECA kinetics will provide a robust approach to resolve the redox ladder in soil biogeochemistry. Existing approaches have imposed the redox ladder following some specific order, e.g., $\mathrm{O}_{2}\left(\mathrm{H}_{2} \mathrm{O}\right), \mathrm{NO}_{3}^{-}\left(\mathrm{N}_{2}\right), \mathrm{MnO}_{2}\left(\mathrm{Mn}^{2+}\right), \mathrm{Fe}(\mathrm{OH})_{3}\left(\mathrm{Fe}^{2+}\right)$, $\mathrm{SO}_{4}^{2-}\left(\mathrm{H}_{2} \mathrm{~S}\right), \mathrm{CO}_{2}\left(\mathrm{CH}_{4}\right)$, and $\mathrm{H}_{2} \mathrm{O}\left(\mathrm{H}_{2}\right)$ (e.g., Grant, 2001). In contrast, SUPECA kinetics will allow all these redox couples to operate concurrently (in any space-time-process unit), a situation that is more consistent with natural soils. Such a feature will also allow microbial biogeochemistry models (most of which are considered to be valid at pore scale) to be valid at the scale of well-mixed bulk soils $\left(\sim \mathrm{cm}^{3}\right)$.

\section{Conclusions}

In this study, we showed that the popular Monod family kinetics and SU kinetics are not scaling consistently for a reaction network involving mixed $A \stackrel{E}{\rightarrow}$ products type and $A+B \stackrel{E}{\rightarrow}$ products type reactions. SUPECA kinetics, by accounting for mass balance constraints of substrates and consumers, is able to represent an arbitrary number of substrates and consumers without changing mathematical formulation. Our numerical tests indicate that SUPECA kinetics is superior to SU kinetics both in numerical accuracy and numerical robustness, particularly under high relative abundances of consumers with respect to substrates (a typical feature in plant-microbial competition for limited soil nutrients; Schimel and Bennett, 2004; Vitousek et al., 2010). SUPECA kinetics was also able to predict the moisture response function of aerobic soil respiration, providing mechanistic insights not available from the response function approach. Finally, because SUPECA kinetics represents measurable microbial traits and the mechanisms by which they affect soil biogeochemical dynamics, we conclude that this approach can benefit interpretation of observed dynamics and thereby improve soil BGC models.

Code and data availability. The source code and data used in this paper are available upon request to the corresponding author. 


\section{Appendix A: Deriving the governing equations}

The law of mass action formulation of the redox reaction (Eq. 8) is

$$
\begin{aligned}
& \frac{\mathrm{d}[E A]}{\mathrm{d} t}=k_{A}^{+}[E][A]+k_{B}^{-}[E A B] \\
& \quad-\left(k_{A}^{-}+k_{B}^{+}[B]\right)[E A] \\
& \frac{\mathrm{d}[E B]}{\mathrm{d} t}=k_{B}^{+}[E][B]+k_{A}^{-}[E A B] \\
& \quad-\left(k_{B}^{-}+k_{A}^{+}[A]\right)[E B] \\
& \frac{\mathrm{d}[E A B]}{\mathrm{d} t}=k_{A}^{+}[E B][A]+k_{B}^{+}[E A][B] \\
& -\left(k_{A}^{-}+k_{B}^{-}+k_{2}^{+}\right)[E A B] \\
& \frac{\mathrm{d}[P]}{\mathrm{d} t}=k_{2}^{+}[E A B] \\
& \frac{\mathrm{d}[A]}{\mathrm{d} t}=-k_{A}^{+}([E]+[E B])[A] \\
& +k_{A}^{-}([E A]+[E A B]) \\
& \frac{\mathrm{d}[B]}{\mathrm{d} t}=-k_{B}^{+}([E]+[E A])[B] \\
& \quad+k_{B}^{-}([E B]+[E A B]) .
\end{aligned}
$$

We now apply the total quasi-steady-state approximation (e.g., Borghans et al., 1996) to obtain the equilibrium chemistry formulation of the system. Specifically, we obtain Eqs. (11)-(13) by, respectively, setting the time derivatives of Eqs. (A1)-(A3) to zero. Equation (9) is obtained by adding together Eqs. (A1), (A3), and (A5), and using the definition of $[A]_{T}$ by Eq. (14). Equation (10) is obtained by adding together Eqs. (A2), (A3), and (A6) with the definition of $[B]_{T}$ by Eq. (15).

\section{Appendix B: Deriving the dual Monod kinetics in}

Eq. (21)

Replacing $[E A]$ in Eq. (17) with that obtained from Eq. (19), we obtain

$[E A B]=\frac{[A]}{K_{A}} \frac{[B]}{K_{B}}[E]$.

By solving $[E A]$ from Eq. (19), $[E B]$ from Eq. (20) and combining these with Eq. (B1) into Eq. (16), we find

$[E]_{T}=\left(1+\frac{[A]}{K_{A}}\right)\left(1+\frac{[B]}{K_{B}}\right)[E]$.

Now we solve $[E]$ from Eq. (B2) and enter the result into Eq. (B1) and then get

$[E A B]=\left(\frac{[A]}{K_{A}+[A]}\right)\left(\frac{[B]}{K_{A}+[B]}\right)[E]_{T}$.

We thence obtain dual Monod kinetics by entering Eq. (B3) into Eq. (9).

\section{Appendix C: Deriving the synthesizing unit kinetics in} Eq. (26)

Since SU kinetics assumes that substrates are not limiting the biogeochemical reaction, we then, from Eqs. (23) and (24), obtain

$$
\begin{aligned}
& {[E A]=\frac{k_{A}^{+}[A]}{k_{B}^{+}[B]}[E]} \\
& {[E B]=\frac{k_{B}^{+}[B]}{k_{A}^{+}[A]}[E] .}
\end{aligned}
$$

By entering Eqs. (C1) and (C2) into Eq. (13), and solving for $[E A B]$, we find

$$
\begin{aligned}
{[E A B] } & =\frac{[E]}{k_{2}^{+}+k_{A}^{-}+k_{B}^{-}}\left(k_{A}^{+}[A]+k_{B}^{+}[B]\right) \\
& =\frac{[E]}{\widetilde{k}_{2}^{+}}\left(k_{A}^{+}[A]+k_{B}^{+}[B]\right),
\end{aligned}
$$

Now, if we combine Eqs. (C1)-(C3) with Eq. (16), we get

$$
\begin{gathered}
{[E]=\frac{[E]_{T}}{1+\frac{k_{A}^{+}[A]}{k_{B}^{+}[B]}+\frac{k_{B}^{+}[B]}{k_{A}^{+}[A]}+\frac{k_{A}^{+}[A]+k_{B}^{+}[B]}{\widetilde{k}_{2}^{+}}},} \\
=\frac{[E]_{T}}{\frac{\left(k_{A}^{+}[A]+k_{B}^{+}[B]\right)^{2}}{\left(k_{A}^{+}[A]\right)\left(k_{B}^{+}[B]\right)}+\frac{k_{A}^{+}[A]+k_{B}^{+}[B]}{\widetilde{k}_{2}^{+}}-1}
\end{gathered}
$$

which, when combined with Eq. (C3), leads to

$$
\begin{aligned}
& {[E A B]=\frac{k_{A}^{+}[A]+k_{B}^{+}[B]}{\widetilde{k}_{2}^{+}} \frac{[E]_{T}}{\frac{\left(k_{A}^{+}[A]+k_{B}^{+}[B]\right)^{2}}{\left(k_{A}^{+}[A]\right)\left(k_{B}^{+}[B]\right)}+\frac{k_{A}^{+}[A]+k_{B}^{+}[B]}{\widetilde{k}_{2}^{+}}-1}} \\
& =\frac{[E]_{T} / \widetilde{k}_{2}^{+}}{\frac{1}{\widetilde{k}_{2}^{+}}+\frac{k_{A}^{+}[A]+k_{B}^{+}[B]}{\left(k_{A}^{+}[A]\right)\left(k_{B}^{+}[B]\right)}-\frac{1}{k_{A}^{+}[A]+k_{B}^{+}[B]}} \\
& =\frac{[E]_{T} / \widetilde{k}_{2}^{+}}{\frac{1}{\tilde{k}_{2}^{+}}+\frac{1}{k_{A}^{+}[A]}+\frac{1}{k_{B}^{+}[B]}-\frac{1}{k_{A}^{+}[A]+k_{B}^{+}[B]}}
\end{aligned}
$$

When $[E A B]$ from eq. (C5) is entered into Eq. (9), we obtain Eq. (26).

\section{Appendix D: Deriving SUPECA kinetics Eq. (28)}

We first derive the set of linear equations using the first-order closure approach (i.e., the perturbation method truncated to first-order accuracy; Shankar, 1994; Tang et al., 2007). By entering Eqs. (14)-(16) into Eq. (23), we have

$$
\begin{aligned}
& k_{B}^{+}[E A]\left([B]_{T}-[E B]-[E A B]\right)=k_{A}^{+} \\
& \quad\left([A]_{T}-[E A]-[E A B]\right) \\
& \quad \times\left([E]_{T}-[E A]-[E B]-[E A B]\right)
\end{aligned}
$$


Now, if we expand Eq. (D1) and keep only the zeroth- and first-order terms of $[E A],[E B]$, and $[E A B]$, we obtain

$$
\begin{gathered}
k_{B}^{+}[B]_{T}[E A]=k_{A}^{+}[E]_{T}\left([A]_{T}-[E A]-[E A B]\right), \\
-k_{A}^{+}[A]_{T}([E A]+[E B]+[E A B])
\end{gathered}
$$

which, after some rearrangement, becomes

$$
\begin{aligned}
& \left(k_{A}^{+}[A]_{T}+k_{A}^{+}[E]_{T}+k_{B}^{+}[B]_{T}\right)[E A]+k_{A}^{+}[A]_{T}[E B] \\
& \quad+k_{A}^{+}\left([A]_{T}+[E]_{T}\right)[E A B]=k_{A}^{+}[A]_{T}[E]_{T}
\end{aligned}
$$

Using the definitions of $f_{A}=k_{A}^{+}[A]_{T}, f_{B}=k_{B}^{+}[B]_{T}$ and $\bar{f}_{A}=f_{A}+k_{A}^{+}[E]_{T}$, we may rewrite Eq. (D3) as

$$
\left(\bar{f}_{A}+f_{B}\right)[E A]+f_{A}[E B]+\bar{f}_{A}[E A B]=f_{A}[E]_{T} .
$$

Because substrates $A$ and $B$ are symmetric in forming the consumer substrate complexes, a similar linear equation can be derived by switching $A$ and $B$ in Eq. (D4) (or by repeating procedures to the derivation of Eq. D4 but using Eqs. 14-16 and 24):

$f_{B}[E A]+\left(f_{A}+\bar{f}_{B}\right)[E B]+\bar{f}_{B}[E A B]=f_{B}[E]_{T}$.

Now, by substituting Eqs. (14)-(16), (23), and (24) into Eq. (25) and assuming $\widetilde{k}_{2}^{+} \approx k_{2}^{+}$(i.e., unbinding is much smaller compared to the product genesis rate), we have

$$
\begin{aligned}
& \left\{k_{A}^{+}\left([A]_{T}-[E A]-[E A B]\right)\right. \\
& \left.\quad+k_{B}^{+}\left([B]_{T}-[E B]-[E A B]\right)\right\} \\
& \times\left([E]_{T}-[E A]-[E B]-[E A B]\right)=k_{2}^{+}[E A B]
\end{aligned}
$$

Once again, by dropping the second- and higher-order terms of the consumer-substrate complexes, Eq. (D6) can be reduced to

$$
\begin{aligned}
& \left(k_{A}^{+}[A]_{T}+k_{B}^{+}[B]_{T}\right)[E]_{T}=\left(k_{A}^{+}[A]_{T}+k_{B}^{+}[B]_{T}\right) \\
& \quad \times([E A]+[E B]+[E A B])+k_{A}^{+}[E]_{T}([E A]+[E A B]), \\
& \quad+k_{B}^{+}[E]_{T}([E B]+[E A B])+k_{2}^{+}[E A B]
\end{aligned}
$$

which by aid of $f_{A}=k_{A}^{+}[A]_{T}, f_{B}=k_{B}^{+}[B]_{T}, \bar{f}_{A}=f_{A}+$ $k_{A}^{+}[E]_{T}, \bar{f}_{B}=f_{B}+k_{B}^{+}[E]_{T}, f_{A B}=f_{A}+f_{B}$, and $\bar{f}_{A B}=$ $\bar{f}_{A}+\bar{f}_{B}$ becomes

$$
\begin{gathered}
\left(\bar{f}_{A}+f_{B}\right)[E A]+\left(f_{A}+\bar{f}_{B}\right)[E B]+\left(k_{2}^{+}+\bar{f}_{A B}\right)[E A B] \\
=f_{A B}[E]_{T} .
\end{gathered}
$$

Now, we solve for $[E A B]$ from the set of linear Eqs. (D4), (D5), and (D8) using Cramer's rule (e.g., Habgood and Arel, 2012) and find

$$
\operatorname{det}\left(M_{d}\right)=\left|\begin{array}{ccc}
\bar{f}_{A}+f_{B} & f_{A} & \bar{f}_{A} \\
f_{B} & f_{A}+\bar{f}_{B} & \bar{f}_{B} \\
\bar{f}_{A}+f_{B} & f_{A}+\bar{f}_{B} & k_{2}^{+}+\bar{f}_{A B}
\end{array}\right|,
$$

and the numerator as

$\operatorname{det}\left(M_{n}\right)=[E]_{T}\left|\begin{array}{ccc}\bar{f}_{A}+f_{B} & f_{A} & f_{A} \\ f_{B} & f_{A}+\bar{f}_{B} & f_{B} \\ \bar{f}_{A}+f_{B} & f_{A}+\bar{f}_{B} & f_{A B}\end{array}\right|$.

Equations (D9) and (D10) together will lead to

$$
\begin{aligned}
& {[E A B]=\frac{\operatorname{det}\left(M_{n}\right)}{\operatorname{det}\left(M_{d}\right)}=} \\
& \frac{f_{A} f_{B} \bar{f}_{A B}[E]_{T}}{k_{2}^{+}\left(f_{A} \bar{f}_{A}+f_{B} \bar{f}_{B}+\bar{f}_{A} \bar{f}_{B}\right)+\bar{f}_{A} \bar{f}_{B} f_{A B}} \\
& =\frac{f_{A} f_{B} \bar{f}_{A B}[E]_{T}}{k_{2}^{+}\left(f_{A B} \bar{f}_{A B}-f_{A} \bar{f}_{B}-\bar{f}_{A} f_{B}+\bar{f}_{A} \bar{f}_{B}\right)+\bar{f}_{A} \bar{f}_{B} f_{A B}}, \\
& =\frac{[E]_{T}}{k_{2}^{+}\left(\frac{f_{A B}}{f_{A} f_{B}}-\frac{f_{A} \bar{f}_{B}+\bar{f}_{A} f_{B}-\bar{f}_{A} \bar{f}_{B}}{f_{A} f_{B} \bar{f}_{A B}}\right)+\frac{\bar{f}_{A} \bar{f}_{B} f_{A B}}{f_{A} f_{B} \bar{f}_{A B}}} \\
& =\frac{[E]_{T} / k_{2}^{+}}{\frac{1}{k_{2}^{+}} \frac{\bar{f}_{A} \bar{f}_{B} f_{A B}}{f_{A} f_{B} \bar{f}_{A B}}+\left(\frac{1}{f_{A}}+\frac{1}{f_{B}}-\frac{f_{A} \bar{f}_{B}+\bar{f}_{A} f_{B}-\bar{f}_{A} \bar{f}_{B}}{f_{A} f_{B} \bar{f}_{A B}}\right)}
\end{aligned}
$$

which, when entered into Eq. (9), leads to Eq. (28).

\section{Appendix E: Deriving SUPECA for a network of substrates and consumers}

In the second equation of Eq. (33), we show that the consumption of a certain substrate as represented in ECA kinetics is determined by the consumer reaction potential $k_{2, i j}^{+}\left[E_{j}\right]_{T}$ multiplied with the relative contribution of the specific consumption pathway with respect to all competing pathways $\left(F_{\mathrm{c}, j}^{\{r\}} /\left(1+F_{r, j}+F_{\mathrm{c}, j}\right)\right)$. Since SUPECA kinetics is a compatible extension of ECA kinetics, SUPECA kinetics should have its numerator indicating the potential reaction rate of the specific pathway, and its denominator indicating the efforts of all interacting pathways. Bearing this partition equivalence in mind, therefore, we assert that $\bar{f}_{A} / k_{2}^{+}$in Eq. (29) should be equivalent to $F_{\mathrm{r}, i}+F_{\mathrm{c}, j}$ in Eq. (33). This assertion then leads to Eqs. (38), (41), and (43) for $A$ substrates. Similarly, Eqs. (39), (42), and (44) are for $B$ substrates. With the definitions of $f_{A} / k_{2}^{+}, f_{B} / k_{2}^{+}$, $\bar{f}_{A} / k_{2}^{+}$and $\bar{f}_{B} / k_{2}^{+}$, using the partition equivalence, we can easily define the network form of $f_{A B}$ in Eq. (40) and the network form of $\bar{f}_{A B}$ in Eq. (45). Further, we observe that the denominator of the last equation in Eq. (28) could be rewritten as $\frac{\left(\bar{f}_{A} / k_{2}^{+}\right)\left(\bar{f}_{B} / k_{2}^{+}\right)\left(f_{A B} / k_{2}^{+}\right)}{\left(\bar{f}_{A B} / k_{2}^{+}\right)}+\left(f_{A B} / k_{2}^{+}\right)-$ $\frac{\left(f_{A} / k_{2}^{+}\right)\left(\bar{f}_{B} / k_{2}^{+}\right)+\left(\bar{f}_{A} / k_{2}^{+}\right)\left(f_{B} / k_{2}^{+}\right)-\left(\bar{f}_{A} / k_{2}^{+}\right)\left(\bar{f}_{B} / k_{2}^{+}\right)}{\left(\bar{f}_{A B} / k_{2}^{+}\right)}$which, after replacing $f_{A} / k_{2}^{+}, f_{B} / k_{2}^{+}, \bar{f}_{A} / k_{2}^{+}, \bar{f}_{B} / k_{2}^{+}, f_{A B} / k_{2}^{+}$, and $\bar{f}_{A B} / k_{2}^{+}$with their corresponding network forms (i.e., Eqs. 38-45), leads to SUPECA kinetics (Eq. 37). 
Appendix F: Formulation of the kinetics-benchmarking problem

Following Eqs. (23)-(25), the EC problem used to benchmark synthesizing unit (SU) and SUPECA predictions is defined as

$k_{B S 1}[B]\left[S_{1}\right]=k_{B S 2}\left[S_{2}\right]\left[B S_{1}\right]$

$k_{B S 2}[B]\left[S_{2}\right]=k_{B S 1}\left[S_{1}\right]\left[B S_{2}\right]$

$k_{B S 1}\left[B S_{2}\right]\left[S_{1}\right]+k_{B S 2}\left[B S_{1}\right]\left[S_{2}\right]=k_{2}^{+}\left[B S_{1} S_{2}\right]$

$K_{M S 1}\left[M S_{1}\right]=[M]\left[S_{1}\right]$,

which are subject to the constraints

$$
\begin{aligned}
& {\left[S_{1}\right]_{T}=\left[S_{1}\right]+\left[M S_{1}\right]+\left[B S_{1}\right]+\left[B S_{1} S_{2}\right]} \\
& {\left[S_{2}\right]_{T}=\left[S_{2}\right]+\left[B S_{2}\right]+\left[B S_{1} S_{2}\right]} \\
& {[B]_{T}=[B]+\left[B S_{1}\right]+\left[B S_{2}\right]+\left[B S_{1} S_{2}\right]} \\
& {[B]_{T}=[B]+\left[B S_{1}\right]+\left[B S_{2}\right]+\left[B S_{1} S_{2}\right] .}
\end{aligned}
$$

To relate these equations to a dynamic system, $S_{1}$ and $S_{2}$ are substrates, $B$ is microbial population, and $M$ is some sorbent that can reversibly adsorb substrate $S_{1}$. The corresponding graphic representation of the problem is available in the Supplement.

For benchmarking, $\left[B S_{1} S_{2}\right]$ is solved from Eqs. (F1)-(F8) using a fixed-point iteration algorithm (see the Supplement) for each set of parameters. Unlike the Newton-Raphson iteration, the fixed-point iteration ensures positive mass of all variables, and mass balance relationships from Eqs. (F5)(F8) are automatically satisfied by the numerical solution.

\section{Appendix G: Derivation of relevant kinetic parameters for the steady state aerobic respiration problem}

The aerobic respiration problem is formulated as

$$
\frac{\mathrm{d}\left[\mathrm{O}_{2}\right]_{\mathrm{g}, \mathrm{s}}}{\mathrm{d} t}=\frac{\left(\left[\mathrm{O}_{2}\right]_{\mathrm{a}}-\left[\mathrm{O}_{2}\right]_{\mathrm{g}, \mathrm{s}}\right)}{\left(R_{\mathrm{a}}+R_{\mathrm{s}}\right) Z}-F\left(B,\left[\mathrm{O}_{2}\right]_{\mathrm{g}, \mathrm{s}}, S, M\right),
$$

where $\left[\mathrm{O}_{2}\right]_{\mathrm{g}, \mathrm{s}}$ is gaseous oxygen concentration in bulk soil. $\left[\mathrm{O}_{2}\right]_{\mathrm{a}}$ is atmospheric oxygen concentration (set to $8.45 \mathrm{~mol} \mathrm{~m}^{-3}$ ), $S$ is dissolvable organic carbon (DOC) concentration (set to $3 \mathrm{~mol} \mathrm{~m}^{-3}$; we note that SUPECA is able to accommodate more specific carbon compounds (like in Riley et al., 2014), yet our recent analysis (Dwivedi et al., 2017) suggests that a lumped DOC is sufficient for simple applications like the one we present here), and $M$ is soil mineral sorbent concentration (with variable values). All concentrations are defined with units $\left(\mathrm{mol} \mathrm{m}^{-3}\right) . R_{\mathrm{a}}$ is aerodynamic resistance, which is set to $50 \mathrm{~s} \mathrm{~m}^{-1} . R_{\mathrm{S}}$ is soil resistance $\left(\mathrm{s} \mathrm{m}^{-1}\right)$ calculated using the approach in Tang and Riley (2013b). Z is soil depth (set to $10 \mathrm{~cm}$, following the incubation set up of Franzluebbers, 1999). $F\left(B,\left[\mathrm{O}_{2}\right]_{\mathrm{g}, \mathrm{s}}, S, M\right)$ is the oxygen consumption rate calculated using SUPECA kinetics, whose kinetic parameters are derived as the following. The steadystate problem is solved by setting the temporal derivative of Eq. (G1) to zero, and solved for $\left[\mathrm{O}_{2}\right]_{\mathrm{g}, \mathrm{s}}$ through iterations. The shape of the flux $F\left(B,\left[\mathrm{O}_{2}\right]_{\mathrm{g}, \mathrm{s}}, S, M\right)$ is then compared to that derived from incubation studies in Franzluebbers (1999).

In this aerobic respiration problem, microbes are assumed to form microsites sitting uniformly inside pores of the bulk soil. $\mathrm{O}_{2}$ approaches the microsites through both aqueous and gaseous diffusion, and only the aqueous phase is used for microbial respiration. These assumptions will lead to the relationship between near-cell aqueous $\mathrm{O}_{2}$ concentration and the diffusive flux:

$$
\begin{aligned}
v_{\mathrm{m}} \frac{\mathrm{d}\left[\mathrm{O}_{2}\right]_{w, 0}}{\mathrm{~d} t} & =-k_{\mathrm{O}_{2}, w, 1}[X]\left[\mathrm{O}_{2}\right]_{w, 0} \\
& +\kappa_{\mathrm{O}_{2}}\left(\left[\mathrm{O}_{2}\right]_{w}-\left[\mathrm{O}_{2}\right]_{0}\right),
\end{aligned}
$$

where the conductance $\kappa_{\mathrm{O}_{2}}$ is

$$
\left(\frac{\kappa_{\mathrm{O}_{2}}}{4 \pi}\right)^{-1}=\frac{\delta}{D_{w, \mathrm{O}_{2}} r_{\mathrm{m}}\left(r_{\mathrm{m}}+\delta\right)}+\frac{1}{D_{\mathrm{O}_{2}}\left(r_{\mathrm{m}}+\delta\right)},
$$

and $r_{\mathrm{m}}$ is the radius of the microsite (or aggregate), $\delta$ is thickness of the water film that covers the microsite (Grant and Rochette, 1994), $v_{\mathrm{m}}$ is the microsite volume $\left(\mathrm{m}^{3} \mathrm{site}^{-1}\right)$, and $\left[\mathrm{O}_{2}\right]$ is the aqueous oxygen concentration in the bulk soil matrix. $[X]$ is the cell density $\left(\mathrm{mol}\right.$ cell site $\left.{ }^{-1}\right)$. The unit of $k_{\mathrm{O}_{2}, 1}$ is then $\mathrm{m}^{3}$ (mol cell) ${ }^{-1} \mathrm{~s}^{-1}$.

The bulk aqueous diffusivity in Eq. (G3) is

$D_{\mathrm{O}_{2}}=\theta D_{\mathrm{O}_{2}, \mathrm{w}}+\frac{\varepsilon}{\alpha_{\mathrm{O}_{2}}} D_{\mathrm{O}_{2}, \mathrm{~g}}$.

Now, if we assume the steady state (also known as $\mathrm{d}\left[\mathrm{O}_{2}\right]_{0} / \mathrm{d} t \approx 0$ ) of Eq. (G2), we obtain

$\left[\mathrm{O}_{2}\right]_{\mathrm{w}, 0}=\frac{\left[\mathrm{O}_{2}\right]_{w}}{1+\frac{k_{\mathrm{O}_{2}, \mathrm{w}, 1}[X]}{\kappa_{\mathrm{O}_{2}}}}$,

which leads to the revised affinity parameter:

$\widetilde{K}_{\mathrm{O}_{2}}=\frac{k_{2}}{k_{\mathrm{O}_{2}, \mathrm{w}, 1}}\left(1+\frac{k_{\mathrm{O}_{2}, \mathrm{w}, 1}[X]_{T}}{\kappa_{\mathrm{O}_{2}}}\right)$,

where the zero-order approximation is made by taking $[X] \approx$ $[X]_{T}$.

Now assume that the ball-like microbe is covered with $N$ disc-like transporters, whose mean radius is $r_{p}$. Assuming that the binding is limited by diffusion, then using the chemoreception theory by Berg and Purcell (1977), we have

$k_{\mathrm{O}_{2}, \mathrm{w}, 1}=4 \pi D_{\mathrm{O}_{2}, \mathrm{w}, 0} r_{\mathrm{c}} \frac{N r_{p}}{N r_{p}+\pi r_{\mathrm{c}}} \operatorname{cell}^{-1}$,

where the term $N r_{p} /\left(N r_{p}+\pi r_{\mathrm{c}}\right)$ accounts for the interference between different transporters of a cell. Thus, assuming 
$[X]_{T}=m$ cell site ${ }^{-1}$, we get

$$
\begin{aligned}
\widetilde{K}_{\mathrm{O}_{2}} & =\frac{k_{2}}{k_{\mathrm{O}_{2}, \mathrm{w}, 1}}\left(1+\frac{k_{\mathrm{O}_{2}, 1}[X]_{T}}{\kappa_{\mathrm{O}_{2}}}\right) \\
& =K_{\mathrm{O}_{2}, \mathrm{w}}\left(1+\frac{N r_{p}}{N r_{p}+\pi r_{\mathrm{c}}} \frac{m r_{\mathrm{c}}}{r_{\mathrm{m}}+\delta}\left(\frac{\delta}{r_{\mathrm{m}}}+\frac{D_{\mathrm{O}_{2}, w, 0}}{D_{\mathrm{O}_{2}}}\right)\right) .
\end{aligned}
$$

With a similar procedure for DOC, we have the following:

$$
\begin{aligned}
\widetilde{K}_{\mathrm{DOC}} & =\frac{k_{2}}{k_{\mathrm{DOC}, \mathrm{w}, 1}}\left(1+\frac{k_{\mathrm{DOC}, \mathrm{w}, 1}[X]_{T}}{\kappa_{\mathrm{DOC}}}\right) \\
& =K_{\mathrm{DOC}}\left(1+\frac{N r_{p}}{N r_{p}+\pi r_{\mathrm{c}}} \frac{m r_{\mathrm{c}}}{r_{\mathrm{m}}+\delta}\left(\frac{\delta}{r_{\mathrm{m}}}+\frac{D_{\mathrm{DOC}, \mathrm{w}, 0}}{D_{\mathrm{DOC}}}\right)\right),
\end{aligned}
$$

and

$$
\begin{gathered}
k_{\mathrm{DOC}, \mathrm{w}, 1}=4 \pi D_{\mathrm{DOC}, w, 0} r_{\mathrm{c}} N_{A} \frac{N r_{p}}{N r_{p}+\pi r_{\mathrm{c}}} \\
(\text { mol cell })^{-1}
\end{gathered}
$$

where $N_{A}=6.02 \times 10^{23} \mathrm{~mol}^{-1}$.

Below, we provide some estimates for the parameters to support the above model of moisture dependence of microbial decomposition. The microbial cell radius $r_{\mathrm{c}}$ is on the order of $10^{-6} \mathrm{~m}$, and $r_{p} / r_{\mathrm{c}}$ is about $10^{-3}$. At $25^{\circ} \mathrm{C}$, the aqueous diffusivity of $\mathrm{O}_{2}$ is about $2.9 \times 10^{-9} \mathrm{~m}^{2} \mathrm{~s}^{-1}$; therefore, assuming $N=3000$ transporters per cell (which covers only $0.3 \%$ of the cell's surface area), we have $k_{\mathrm{O}_{2}, \mathrm{w}, 1}=1.0 \times 10^{10} \mathrm{~m}^{3}(\text { mol cell })^{-1} \mathrm{~s}^{-1}$. Similarly, since the aqueous diffusivity of DOC is about $10^{-9} \mathrm{~m}^{2} \mathrm{~s}^{-1}$, assuming $N=3000$ transporters per cell, we have $k_{\mathrm{DOC}, \mathrm{w}, 1}=$ $3.7 \times 10^{9} \mathrm{~m}^{3}$ (mol cell $)^{-1} \mathrm{~s}^{-1}$. Suppose the respiration is bottlenecked by a single respiratory enzyme, and since the enzyme activity varies on the order of $10-1000 \mathrm{~s}^{-1}$ (English et al., 2006), then by taking $k_{2}=100 N \mathrm{~s}^{-1}=3 \times 10^{5} \mathrm{~s}^{-1}$ per cell, we have $K_{\mathrm{O}_{2}, \mathrm{w}}=3 \times 10^{-5} \mathrm{~mol} \mathrm{~m}^{-3}$, which agrees well with parameters reported for microbes in aqueous solutions in Button (1985). However, Grant (1991) estimated $K_{\mathrm{O}_{2}, \mathrm{w}}=3.0 \times 10^{-3} \mathrm{~mol} \mathrm{~m}^{-3}$; Borden and Bedient (1986) estimated $K_{\mathrm{O}_{2} \text {, w }}=3.1 \times 10^{-3} \mathrm{~mol} \mathrm{~m}^{-3}$ for application in soil. We therefore elevated the numerical value to $K_{\mathrm{O}_{2} \text {, w }}=3.0 \times$ $10^{-3} \mathrm{~mol} \mathrm{~m}^{-3}$. According to Eqs. (G7) and (G8), such elevation could occur either by increasing the maximum substrate processing rate $k_{2}$ or decreasing the diffusion $k_{\mathrm{O}_{2}, \mathrm{w}, 1}$ controlled parameter (through the formation of micropores in aggregates; e.g., Kausch and Pallud, 2013; Yang et al., 2014). Based on similar magnitude analysis, we obtain $K_{\text {DOC, w }}=$ $8.1 \times 10^{-5} \mathrm{~mol} \mathrm{~m}^{-3}$, which falls to the lower end of the values reported for many hydrocarbon compounds as reported in Button (1985). We did not elevate the value of $K_{\mathrm{DOC} \text {, w }}$ because it could vary over 4 orders of magnitude (Button, 1985), and our number leads to a good fit between model predictions and data.
Taking all these numbers together, we have

$$
\begin{gathered}
\widetilde{K}_{\mathrm{O}_{2}, \mathrm{w}}=K_{\mathrm{O}_{2}, \mathrm{w}}\left(1+0.48 \times \frac{m r_{\mathrm{c}}}{r_{\mathrm{m}}+\delta}\left(\frac{\delta}{r_{\mathrm{m}}}+\frac{D_{\mathrm{O}_{2}, \mathrm{w}, 0}}{D_{\mathrm{O}_{2}}}\right)\right) \\
=3 \times 10^{-3}\left(1+0.48 \times \frac{m r_{\mathrm{c}}}{r_{\mathrm{m}}+\delta}\left(\frac{\delta}{r_{\mathrm{m}}}+\frac{D_{\mathrm{O}_{2}, \mathrm{w}, 0}}{D_{\mathrm{O}_{2}}}\right)\right) \\
\widetilde{K}_{\mathrm{DOC}}=K_{\mathrm{DOC}}\left(1+0.48 \times \frac{m r_{\mathrm{c}}}{r_{\mathrm{m}}+\delta}\left(\frac{\delta}{r_{\mathrm{m}}}+\frac{D_{\mathrm{DOC}, \mathrm{w}, 0}}{D_{\mathrm{DOC}}}\right)\right) . \\
=8.1 \times 10^{-5}\left(1+0.48 \times \frac{m r_{\mathrm{c}}}{r_{\mathrm{m}}+\delta}\left(\frac{\delta}{r_{\mathrm{m}}}+\frac{D_{\mathrm{DOC}, \mathrm{w}, 0}}{D_{\mathrm{DOC}}}\right)\right)
\end{gathered}
$$

Since, at $25^{\circ} \mathrm{C}$, the Bunsen solubility coefficient of oxygen is 0.032 , we have

$$
\begin{aligned}
\widetilde{K}_{\mathrm{O}_{2}, \mathrm{~g}} & =\frac{\widetilde{K}_{\mathrm{O}_{2}, \mathrm{w}}}{0.032}=9.4 \times 10^{-2}\left(1+0.48 \times \frac{m r_{\mathrm{c}}}{r_{\mathrm{m}}+\delta}\right. \\
& \left.\left(\frac{\delta}{r_{\mathrm{m}}}+\frac{D_{\mathrm{O}_{2}, \mathrm{w}, 0}}{D_{\mathrm{O}_{2}}}\right)\right) .
\end{aligned}
$$

The water film thickness is a function of soil water potential (Tokunaga, 2009) and we calculate it using the approach in ECOSYS (Grant, 2001), which is

$$
\delta=\max \left(10^{-6}, \exp (-13.65-0.857 \log (-\psi))\right),
$$

where the soil matric potential is in meters, and water film thickness is restricted to at least $1 \mu \mathrm{m}$.

For model applications, microbes are often in units of mol C m${ }^{-3}$. Bratbak and Dundas (1984) reported that the wet biomass density of bacteria is over the range $1.1-1.2 \mathrm{~g} \mathrm{~cm}^{-3}$, of which about $40 \%$ is dry biomass, and about $50 \%$ of dry biomass is carbon. Therefore, with the medium cell density $1.15 \mathrm{~g} \mathrm{~cm}^{-3}, 1 \mathrm{~mol} \mathrm{C} \mathrm{m}^{-3}$ microbial biomass is about $52.17 \mathrm{~cm}^{3}$; by further taking $r_{\mathrm{c}}=10^{-6} \mathrm{~m}=10^{-4} \mathrm{~cm}$, the cell number density is $2.1 \times 10^{-11} \mathrm{~mol}$ cell m $\mathrm{m}^{-3}$. Therefore, for $k_{2}=100 \mathrm{~s}^{-1}$ per porter, given each cell has 3000 transporters, the maximum respiration rate is $6.3 \times 10^{-6} \mathrm{~s}^{-1}$ for $1 \mathrm{~mol} \mathrm{C} \mathrm{m}{ }^{-3}$ dry microbial biomass, which was then elevated to $3.8 \times 10^{-4} \mathrm{~s}^{-1}$ to obtain a better fit between data and model prediction. This required elevation in maximum respiration rate indicates that the data as obtained (after 24 days of incubation) in Franzluebbers (1999) are representative of fastgrowing microbes. 


\section{The Supplement related to this article is available online at https://doi.org/10.5194/gmd-10-3277-2017- supplement.}

Author contributions. J-YT designed the theory and conducted the analysis. J-YT and WJR discussed the results and wrote the paper.

Competing interests. The authors declare that they have no conflict of interest.

Acknowledgements. This research was supported by the Director, Office of Science, Office of Biological and Environmental Research of the US Department of Energy under contract no. DE-AC0205CH11231 as part of the Accelerated Climate Model for Energy in the Earth system modeling program and the Next Generation Ecosystem Experiment-Arctic project. Financial support does not constitute an endorsement by the Department of Energy of the views expressed in this study.

Edited by: Jason Williams

Reviewed by: four anonymous referees

\section{References}

Achat, D. L., Augusto, L., Gallet-Budynek, A., and Loustau, D.: Future challenges in coupled C-N-P cycle models for terrestrial ecosystems under global change: a review, Biogeochem., 131, 173-202, https://doi.org/10.1007/s10533-016-0274-9, 2016.

Aksnes, D. L. and Egge, J. K.: A theoretical-model for nutrientuptake in phytoplankton, Mar. Ecol. Prog. Ser., 70, 65-72, 1991.

Allison, S. D.: A trait-based approach for modelling microbial litter decomposition, Ecol. Lett., 15, 1058-1070, 2012.

Armstrong, R. A.: Nutrient uptake rate as a function of cell size and surface transporter density: A Michaelis-like approximation to the model of Pasciak and Gavis, Deep-Sea Res. Pt. I, 55, 13111317, 2008.

Arora, V. K., Boer, G. J., Friedlingstein, P., Eby, M., Jones, C. D., Christian, J. R., Bonan, G., Bopp, L., Brovkin, V., Cadule, P., Hajima, T., Ilyina, T., Lindsay, K., Tjiputra, J. F., and Wu, T.: Carbon-Concentration and Carbon-Climate Feedbacks in CMIP5 Earth System Models, J. Climate, 26, 5289-5314, 2013.

Batjes, N. H.: Harmonized soil property values for broad-scale modelling (WISE30sec) with estimates of global soil carbon stocks, Geoderma, 269, 61-68, 2016.

Berg, H. C. and Purcell, E. M.: Physics of Chemoreception, Biophys. J., 20, 193-219, 1977.

Blanke, J. H., Lindeskog, M., Lindstrom, J., and Lehsten, V.: Effect of climate data on simulated carbon and nitrogen balances for Europe, J. Geophys. Res.-Biogeo., 121, 1352-1371, 2016.

Bonachela, J. A., Raghib, M., and Levin, S. A.: Dynamic model of flexible phytoplankton nutrient uptake, P. Natl. Acad. Sci. USA, 108, 20633-20638, 2011.
Borden, R. C. and Bedient, P. B.: Transport of dissolved hydrocarbons influenced by oxygen-limited biodegradation .1. Theoretical development, Water Resour. Res., 22, 1973-1982, 1986.

Borghans, J. A. M., DeBoer, R. J., and Segel, L. A.: Extending the quasi-steady state approximation by changing variables, B. Math. Biol., 58, 43-63, 1996.

Bouskill, N. J., Tang, J. Y., Riley, W. J., and Brodie, E. L.: Traitbased representation of biological nitr fication: model development testing, and predicted community composition, Front. Microbiol., 3, https://doi.org/10.3389/fmicb.2012.00364, 2012.

Bouskill, N. J., Riley, W. J., and Tang, J. Y.: Meta-analysis of highlatitude nitrogen-addition and warming studies implies ecological mechanisms overlooked by land models, Biogeosciences, 11, 6969-6983, https://doi.org/10.5194/bg-11-6969-2014, 2014.

Brandt, B. W., van Leeuwen, I. M. M., and Kooijman, S. A. L. M.: A general model for multiple substrate biodegradation. Application to co-metabolism of structurally non-analogous compounds, Water Res., 37, 4843-4854, 2003.

Bratbak, G. and Dundas, I.: Bacterial dry-matter content and biomass estimations, Appl. Environ. Microb., 48, 755-757, 1984.

Briggs, G. E. and Haldane, J. B. S.: A note on the kinetics of enzyme action, Biochem. J., 19, 338-339, 1925.

Button, D. K.: Kinetics of nutrient-limited transport and microbialgrowth, Microbiol. Rev., 49, 270-297, 1985.

Chellaboina, V., Bhat, S. P., Haddad, W. M., and Bernstein, D. S.: Modeling and analysis of mass-action kinetics, nonnegativity, realizability, reducibility, and semistability, IEEE Contr. Syst. Mag., 29, 60-78, 2009.

Ciais, P., Gasser, T., Paris, J. D., Caldeira, K., Raupach, M. R., Canadell, J. G., Patwardhan, A., Friedlingstein, P., Piao, S. L., and Gitz, V.: Attributing the increase in atmospheric $\mathrm{CO}_{2}$ to emitters and absorbers, Nat. Clim. Change, 3, 926-930, 2013.

Coleman, K. and Jenkinson, D. S.: RothC-26.3 - A model for the turnover of carbon in soil: model description and windows users guide: November 1999 issue, Lawes Agricultural Trust, Harpenden, UK, 1999.

Dwivedi, D., Riley, W. J., Torn, M. S., Spycher, N., Maggi, F., and Tang, J. Y.: Mineral properties, microbes, transport, and plantinput profiles control vertical distribution and age of soil carbon stocks, Soil Biol. Biochem., 107, 244-259, 2017.

English, B. P., Min, W., van Oijen, A. M., Lee, K. T., Luo, G. B., Sun, H. Y., Cherayil, B. J., Kou, S. C., and Xie, S. N.: Everfluctuating single enzyme molecules: Michaelis-Menten equation revisited (vol 2, pg 87, 2006), Nat. Chem. Biol., 2, 168-168, 2006.

Feynman, R. P., Leighton, R. B., and Sands, M.: The Feynman lectures on physics: Vol. I., Addison-Wesley Publishing Company, Inc., Reading, Massachusetts, 1963.

Follows, M. J., Dutkiewicz, S., Grant, S., and Chisholm, S. W.: Emergent biogeography of microbial communities in a model ocean, Science, 315, 1843-1846, https://doi.org/10.1126/science.1138544, 2007.

Franzluebbers, A. J.: Microbial activity in response to water-filled pore space of variably eroded southern Piedmont soils, Appl. Soil Ecol., 11, 91-101, 1999.

Friedlingstein, P., Meinshausen, M., Arora, V. K., Jones, C. D., Anav, A., Liddicoat, S. K., and Knutti, R.: Uncertainties in CMIP5 Climate Projections due to carbon cycle feedbacks, J. Climate, 27, 511-526, 2014. 
Grant, R. F.: A Technique for estimating denitrification rates at different soil temperatures, water Contents, and nitrate concentrations, Soil Sci., 152, 41-52, 1991.

Grant, R. F.: A review of the canadian ecosystem Model-Ecosys, in: Modeling carbon and nitrogen dynamics for soil management, CRC Press, Boca, Raton, 173-264, 2001.

Grant, R. F.: Modelling changes in nitrogen cycling to sustain increases in forest productivity under elevated atmospheric $\mathrm{CO}_{2}$ and contrasting site conditions, Biogeosciences, 10, 7703-7721, https://doi.org/10.5194/bg-10-7703-2013, 2013.

Grant, R. F. and Rochette, P.: Soil microbial respiration at different water potentials and temperatures - theory and mathematicalmodeling, Soil Sci. Soc. Am. J., 58, 1681-1690, 1994.

Grant, R. F., Juma, N. G., and Mcgill, W. B.: Simulation of Carbon and Nitrogen Transformations in Soil - Mineralization, Soil Biol. Biochem., 25, 1317-1329, https://doi.org/10.1016/00380717(93)90046-E, 1993.

Griffin, D. M.: A Theoretical study relating concentration and diffusion of oxygen to biology of organisms in soil, New Phytol., 67, 561-577, 1968.

Gross, D., Shortle, J. F., Thompson, J. M., and Harris, C. M.: Fundamentals of queueing theory, Wiley series in probability and statistics, ISBN: 978-1-118-21164-9, 2011.

Habgood, K. and Arel, I.: A condensation-based application of Cramer's rule for solving large-scale linear systems, J. Discrete Algorithms, 10, 98-109, https://doi.org/10.1016/.j.jda.2011.06.007, 2012.

He, Y. J., Trumbore, S. E., Torn, M. S., Harden, J. W., Vaughn, L. J. S., Allison, S. D., and Randerson, J. T.: Radiocarbon constraints imply reduced carbon uptake by soils during the 21 st century, Science, 353, 1419-1424, 2016.

Holling, C. S.: Some characteristics of simple types of predation and parasitism, Can. Entomol., 91, 385-398, https://doi.org/10.4039/Ent91385-7, 1959.

Holling, C. S.: The functional response of invertebrate predators to prey density, Mem. Entomol. Soc. Can., 48, 1-86, 1966.

Kausch, M. F. and Pallud, C. E.: Modeling the impact of soil aggregate size on selenium immobilization, Biogeosciences, 10, 13231336, https://doi.org/10.5194/bg-10-1323-2013, 2013.

Keiluweit, M., Nico, P. S., Kleber, M., and Fendorf, S.: Are oxygen limitations under recognized regulators of organic carbon turnover in upland soils?, Biogeochem., 127, 157-171, https://doi.org/10.1007/s10533-015-0180-6, 2016.

Kolditz, O., Ratke, R., Diersch, H. J. G., and Zielke, W.: Coupled groundwater flow and transport .1. Verification of variable density flow and transport models, Adv. Water Resour., 21, 27-46, 1998.

Kooijman, S.: Dynamic energy budget theory for metabolic organisation, Cambridge University Press, Cambridge, 2010.

Kooijman, S. A. L. M.: The Synthesizing Unit as model for the stoichiometric fusion and branching of metabolic fluxes, Biophys. Chem., 73, 179-188, 1998.

Koven, C. D., Riley, W. J., Subin, Z. M., Tang, J. Y., Torn, M. S., Collins, W. D., Bonan, G. B., Lawrence, D. M., and Swenson, S. C.: The effect of vertically resolved soil biogeochemistry and alternate soil $\mathrm{C}$ and $\mathrm{N}$ models on C dynamics of CLM4, Biogeosciences, 10, 7109-7131, https://doi.org/10.5194/bg-107109-2013, 2013.
Le Roux, X., Bouskill, N. J., Niboyet, A., Barthes, L., Dijkstra, P., Field, C. B., Hungate, B. A., Lerondelle, C., Pommier, T., Tang, J. Y., Terada, A., Tourna, M., and Poly, F.: Predicting the responses of soil nitrite-oxidizers to multi-factorial global change: A trait-based approach, Front. Microbiol., 7, 628, https://doi.org/10.3389/fmicb.2016.00628, 2016.

Litchman, E. and Klausmeier, C. A.: Trait-based community ecology of phytoplankton, Annu. Rev. Ecol. Evol. S., 39, 615-639, 2008.

Luo, Z., Wang, E., Zheng, H., Baldock, J. A., Sun, O. J., and Shao, Q.: Convergent modelling of past soil organic carbon stocks but divergent projections, Biogeosciences, 12, 43734383, https://doi.org/10.5194/bg-12-4373-2015, 2015.

Maggi, F. and Riley, W. J.: Transient competitive complexation in biological kinetic isotope fractionation explains nonsteady isotopic effects: Theory and application to denitrification in soils, J. Geophys. Res.-Biogeo., 114, G04012, https://doi.org/10.1029/2008jg000878, 2009.

Manzoni, S., Moyano, F., Katterer, T., and Schimel, J.: Modeling coupled enzymatic and solute transport controls on decomposition in drying soils, Soil Biol. Biochem., 95, 275-287, 2016.

Mao, X., Prommer, H., Barry, D. A., Langevin, C. D., Panteleit, B., and Li, L.: Three-dimensional model for multi-component reactive transport with variable density groundwater flow, Environ. Modell. Softw., 21, 615-628, 2006.

Melillo, J. M., Aber, J. D., Linkins, A. E., Ricca, A., Fry, B., and Nadelhoffer, K. J.: Carbon and Nitrogen Dynamics Along the Decay Continuum - Plant Litter to Soil Organic-Matter, Plant Soil, 115, 189-198, https://doi.org/10.1007/Bf02202587, 1989.

Merico, A., Bruggeman, J., and Wirtz, K.: A traitbased approach for downscaling complexity in plankton ecosystem models, Ecol. Model., 220, 3001-3010, https://doi.org/10.1016/j.ecolmodel.2009.05.005, 2009.

Michaelis, L. and Menten, M. L.: The kenetics of the inversion effect, Biochem. Z., 49, 333-369, 1913.

Monod, J.: The growth of bacterial cultures, Annu. Rev. Microbiol., 3, 371-394, 1949.

Murdoch, W. W.: Functional response of predators, J. Appl. Ecol., 10, 335-342, 1973.

Niu, S. L., Classen, A. T., Dukes, J. S., Kardol, P., Liu, L. L., Luo, Y. Q., Rustad, L., Sun, J., Tang, J. W., Templer, P. H., Thomas, R. Q., Tian, D. S., Vicca, S., Wang, Y. P., Xia, J. Y., and Zaehle, S.: Global patterns and substrate-based mechanisms of the terrestrial nitrogen cycle, Ecol. Lett., 19, 697-709, https://doi.org/10.1111/ele.12591, 2016.

Oleson, K. W., Lawrence, D. W., Bonan, G. B., Brewniak, B., Huang, M., Koven, C. D., Levis, S., Li, F., Riley, W. J., Subin, Z. M., Swenson, S. C., Thornton, P. E., Bozbiyik, A., Fisher, R., Kluzek, E., Lamarque, J. F., Lawrence, P. J., Leung, L. R., Muszala, S., Ricciuto, D. M., Sacks, W., Tang, J. Y., and Yang, Z. L.: Technical description of version 4.5 of the Community Land Model (CLM). Ncar TechRep., Note NCAR/TN-503+ STR. National Center for Atmospheric Research, Boulder, CO, 422 pp., https://doi.org/10.5065/D6RR1W7M, 2013.

Parton, W. and Rasmussen, P.: Long-term effects of crop management in wheat-fallow: II. CCENTURY model simulations, Soil Sci. Soc. Am. J., 58, 530-536, 1994.

Pedersen, M. G., Bersani, A. M., and Bersani, E.: Quasi steadystate approximations in complex intracellular signal transduction 
networks - a word of caution, J. Math. Chem., 43, 1318-1344, 2008.

Pyun, C. W.: Steady-state and equilibrium approximations in chemical kinetics, J. Chem. Educ., 48, 194, https://doi.org/10.102/ed048p194, 1971.

Qian, Y., Yan, H. P., Hou, Z. S., Johannesson, G., Klein, S., Lucas, D., Neale, R., Rasch, P., Swiler, L., Tannahill, J., Wang, H. L., Wang, M. H., and Zhao, C.: Parametric sensitivity analysis of precipitation at global and local scales in the Community Atmosphere Model CAM5, J. Adv. Model Earth Sy., 7, 382-411, 2015.

Renault, P. and Stengel, P.: Modeling oxygen diffusion in aggregated Soils .1. Anaerobiosis inside the aggregates, Soil Sci. Soc. Am. J., 58, 1017-1023, 1994.

Resat, H., Bailey, V., McCue, L. A., and Konopka, A.: Modeling microbial dynamics in heterogeneous environments: growth on soil carbon sources, Microb. Ecol., 63, 883-897, https://doi.org/10.1007/s00248-011-9965-x, 2012.

Reuveni, S., Urbakh, M., and Klafter, J.: Role of substrate unbinding in Michaelis-Menten enzymatic reactions, P. Natl. Acad. Sci. USA, 111, 4391-4396, 2014.

Riley, W. J., Subin, Z. M., Lawrence, D. M., Swenson, S. C., Torn, M. S., Meng, L., Mahowald, N. M., and Hess, P.: Barriers to predicting changes in global terrestrial methane fluxes: analyses using CLM4Me, a methane biogeochemistry model integrated in CESM, Biogeosciences, 8, 1925-1953, https://doi.org/10.5194/bg-8-1925-2011, 2011.

Riley, W. J., Maggi, F., Kleber, M., Torn, M. S., Tang, J. Y., Dwivedi, D., and Guerry, N.: Long residence times of rapidly decomposable soil organic matter: application of a multi-phase, multi-component, and vertically resolved model (BAMS1) to soil carbon dynamics, Geosci. Model Dev., 7, 1335-1355, https://doi.org/10.5194/gmd-7-1335-2014, 2014.

Schimel, J. P. and Bennett, J.: Nitrogen mineralization: Challenges of a changing paradigm, Ecology, 85, 591-602, 2004.

Schnell, S. and Maini, P. K.: Enzyme kinetics at high enzyme concentration, B Math. Biol., 62, 483-499, 2000.

Schnell, S. and Mendoza, C.: Enzyme kinetics of multiple alternative substrates, J. Math. Chem., 27, 155-170, 2000.

Shankar, R.: Principles of quantum mechanics, second edition, Springer, ISBN 978-1-4757-0578-2, 1994.

Shao, P., Zeng, X. B., Sakaguchi, K., Monson, R. K., and Zeng, X. D.: Terrestrial carbon cycle: climate relations in eight CMIP5 earth system models, J. Climate, 26, 8744-8764, 2013.

Shi, M., Fisher, J. B., Brzostek, E. R., and Phillips, R. P.: Carbon cost of plant nitrogen acquisition: global carbon cycle impact from an improved plant nitrogen cycle in the Community Land Model, Glob. Change Biol., 22, 1299-1314, https://doi.org/10.1111/gcb.13131, 2016.

Sierra, C. A., Trumbore, S. E., Davidson, E. A., Vicca, S., and Janssens, I.: Sensitivity of decomposition rates of soil organic matter with respect to simultaneous changes in temperature and moisture, J. Adv. Model Earth Sy., 7, 335-356, https://doi.org/10.1002/2014ms000358, 2015.

Smith, O. L.: Analytical Model of the Decomposition of Soil Organic-Matter, Soil Biol. Biochem., 11, 585-606, https://doi.org/10.1016/0038-0717(79)90027-0, 1979.

Sols, A. and Marco, R.: Concentrations of metabolites and binding sites. Implications in metabolic regulation, in: Current Topics in
Cellular Regulation, Vol. 2, edited by: Horecker, B. and Stadtman, E., New York, Academic Press, 227-273, 1970.

Sulman, B. N., Phillips, R. P., Oishi, A. C., Shevliakova, E., and Pacala, S. W.: Microbe-driven turnover offsets mineral-mediated storage of soil carbon under elevated $\mathrm{CO}_{2}$, Nat. Clim. Change, 4 , 1099-1102, 2014.

Tang, J., Zhuang, Q., Shannon, R. D., and White, J. R.: Quantifying wetland methane emissions with process-based models of different complexities, Biogeosciences, 7, 3817-3837, https://doi.org/10.5194/bg-7-3817-2010, 2010.

Tang, J. Y.: On the relationships between the Michaelis-Menten kinetics, reverse Michaelis-Menten kinetics, equilibrium chemistry approximation kinetics, and quadratic kinetics, Geosci. Model Dev., 8, 3823-3835, https://doi.org/10.5194/gmd-8-38232015, 2015.

Tang, J. Y. and Zhuang, Q. L.: Equifinality in parameterization of process-based biogeochemistry models: A significant uncertainty source to the estimation of regional carbon dynamics, J. Geophys. Res.-Biogeo., 113, G04010, https://doi.org/10.1029/2008JG000757, 2008.

Tang, J. Y. and Zhuang, Q. L.: A global sensitivity analysis and Bayesian inference framework for improving the parameter estimation and prediction of a process-based Terrestrial Ecosystem Model, J. Geophys. Res.-Atmos., 114, D15303, https://doi.org/10.1029/2009JD011724, 2009.

Tang, J. Y. and Riley, W. J.: A total quasi-steady-state formulation of substrate uptake kinetics in complex networks and an example application to microbial litter decomposition, Biogeosciences, 10, 8329-8351, https://doi.org/10.5194/bg-10-83292013, 2013a.

Tang, J. Y. and Riley, W. J.: A new top boundary condition for modeling surface diffusive exchange of a generic volatile tracer: theoretical analysis and application to soil evaporation, Hydrol. Earth Syst. Sci., 17, 873-893, https://doi.org/10.5194/hess-17873-2013, 2013b.

Tang, J. Y., Tang, J., and Wang, Y.: Analytical investigation on 3D non-Boussinesq mountain wave drag for wind profiles with vertical variations, Appl. Math. Mech.-Engl., 28, 317-325, 2007.

Tang, J. Y. and Riley, W. J.: Weaker soil carbon-climate feedbacks resulting from microbial and abiotic interactions, Nat. Clim. Change, 5, 56-60, 2015.

Tang, J. Y. and Riley, W. J.: Technical Note: A generic lawof-the-minimum flux limiter for simulating substrate limitation in biogeochemical models, Biogeosciences, 13, 723-735, https://doi.org/10.5194/bg-13-723-2016, 2016.

Tang, J. Y., Riley, W. J., Koven, C. D., and Subin, Z. M.: CLM4BeTR, a generic biogeochemical transport and reaction module for CLM4: model development, evaluation, and application, Geosci. Model Dev., 6, 127-140, https://doi.org/10.5194/gmd-6127-2013, 2013.

Tilman, D.: Resource competition and community structure, Princeton University Press, Princeton, New Jersey, 1982.

Todd-Brown, K. E. O., Randerson, J. T., Post, W. M., Hoffman, F. M., Tarnocai, C., Schuur, E. A. G., and Allison, S. D.: Causes of variation in soil carbon simulations from CMIP5 Earth system models and comparison with observations, Biogeosciences, 10, 1717-1736, https://doi.org/10.5194/bg-10-1717-2013, 2013 
Tokunaga, T. K.: Hydraulic properties of adsorbed water films in unsaturated porous media, Water Resour. Res., 45, W06415, https://doi.org/10.1029/2009WR007734, 2009.

Van Slyke, D. D. and Cullen, G. E.: The mode of action of urease and of enzymes in general, J. Biol. Chem., 19, 141-180, 1914.

van Werkhoven, K., Wagener, T., Reed, P., and Tang, Y.: Sensitivity-guided reduction of parametric dimensionality for multi-objective calibration of watershed models, Adv. Water Resour., 32, 1154-1169, 2009.

Vitousek, P.: Nutrient cycling and nutrient use efficiency, Am. Nat., 119, 553-572, 1982.

Vitousek, P. M., Porder, S., Houlton, B. Z., and Chadwick, O. A.: Terrestrial phosphorus limitation: mechanisms, implications, and nitrogen-phosphorus interactions, Ecol. Appl., 20, 5-15, 2010.

Wang, Y. P., Leuning, R., Cleugh, H. A., and Coppin, P. A.: Parameter estimation in surface exchange models using nonlinear inversion: how many parameters can we estimate and which measurements are most useful?, Glob. Change Biol., 7, 495-510, 2001.

Wieder, W. R., Bonan, G. B., and Allison, S. D.: Global soil carbon projections are improved by modelling microbial processes, Nat. Clim. Change, 3, 909-912, 2013.

Wieder, W. R., Grandy, A. S., Kallenbach, C. M., and Bonan, G. B.: Integrating microbial physiology and physio-chemical principles in soils with the MIcrobial-MIneral Carbon Stabilization (MIMICS) model, Biogeosciences, 11, 3899-3917, https://doi.org/10.5194/bg-11-3899-2014, 2014.

Wieder, W. R., Cleveland, C. C., Lawrence, D. M., and Bonan, G. B.: Effects of model structural uncertainty on carbon cycle projections: biological nitrogen fixation as a case study, Environ. Res. Lett., 10, 044016, https://doi.org/10.1088/17489326/10/4/044016, 2015a.

Wieder, W. R., Allison, S. D., Davidson, E. A., Georgiou, K., Hararuk, O., He, Y. J., Hopkins, F., Luo, Y. Q., Smith, M. J., Sulman, B., Todd-Brown, K., Wang, Y. P., Xia, J. Y., and Xu, X. F.: Explicitly representing soil microbial processes in Earth system models, Global Biogeochem. Cy., 29, 1782-1800, 2015 b.
Wieder, W. R., Cleveland, C. C., Smith, W. K., and Todd-Brown, K.: Future productivity and carbon storage limited by terrestrial nutrient availability, Nat. Geosci., 8, 441-444, $2015 \mathrm{c}$.

Williams, M., Schwarz, P. A., Law, B. E., Irvine, J., and Kurpius, M. R.: An improved analysis of forest carbon dynamics using data assimilation, Glob. Change Biol., 11, 89-105, 2005.

Williams, P. J.: Validity of application of simple kinetic analysis to heterogeneous microbial populations, Limnol. Oceanogr., 18, 159-164, 1973.

Yang, X. F., Richmond, M. C., Scheibe, T. D., Perkins, W. A., and Resat, H.: Flow partitioning in fully saturated soil aggregates, Transport. Porous. Med., 103, 295-314, 2014.

Yeh, G. T., Burgos, W. D., and Zachara, J. M.: Modeling and measuring biogeochemical reactions: system consistency, data needs, and rate formulations, Adv. Environ. Res., 5, 219-237, 2001.

Zhu, Q. and Riley, W. J.: Improved modelling of soil nitrogen losses, Nat. Clim. Change, 5, 705-706, 2015.

Zhu, Q., Riley, W. J., Tang, J., and Koven, C. D.: Multiple soil nutrient competition between plants, microbes, and mineral surfaces: model development, parameterization, and example applications in several tropical forests, Biogeosciences, 13, 341-363, https://doi.org/10.5194/bg-13-341-2016, 2016a.

Zhu, Q., Iversen, C. M., Riley, W. J., Slette, I. J., and Vander Stel, H. M.: Root traits explain observed tundra vegetation nitrogen uptake patterns: Implications for trait-based land models, J. Geophys. Res.-Biogeo., 121, 3101-3112, https://doi.org/10.1002/2016JG003554, 2016b.

Zhu, Q., Riley, W. J., and Tang, J. Y.: A new theory of plant-microbe nutrient competition resolves inconsistencies between observations and model predictions, Ecol. Appl., 27, 875-886, 2017. 